\title{
Energetics of Winter Troughs Entering South America
}

\author{
EVERSON DAL PIVA \\ Universidade Federal de Santa Maria, Santa Maria, Brazil \\ MANoEl A. Gan AND V. BRahmananda RaO \\ Centro de Previsão de Tempo e Estudos Climáticos, Instituto Nacional de Pesquisas Espaciais, \\ São José dos Campos, Brazil
}

(Manuscript received 11 February 2009, in final form 15 October 2009)

\begin{abstract}
The energetics and behavior of midtropospheric troughs over the Southern Hemisphere and their relationship with South America surface cyclogenesis were studied during the winters of 1999-2003. All surface cyclogenesis situations over Uruguay and adjacent areas associated with $500-\mathrm{hPa}$ troughs were analyzed. The atmospheric circulation associated with type- $\mathrm{B}$ and type-C cyclones form the basis for two composites: composite B (with 25 cases) and composite $\mathrm{C}$ (with 13 cases). The results showed that the midtropospheric troughs were more intense in composite $\mathrm{C}$ than in composite $\mathrm{B}$ before the surface cyclogenesis and that the opposite occurred during the surface cyclogenesis. The baroclinic conversion was dominant in both composites. In composite $\mathrm{B}$, the ageostrophic flux convergence (AFC) contributed positively to the intensification of the surface cyclone since it imported energy into the area before the cyclogenesis started. But in composite $\mathrm{C}$, the AFC served as a sink because it exported energy. Based on these results, it can be concluded that (i) the trough was crucial for the cyclogenesis; (ii) the variables in the mid- and upper levels did not differ significantly from one composite to another; (iii) the northerly heat and moisture flow acted as a preconditioning for the cyclogenesis, mainly for composite C; (iv) the baroclinic conversion dominated the energetics; and (v) the $\mathrm{AFC}$ had only a secondary role, contributing negatively to the development of the cyclone in composite $\mathrm{C}$ and positively to the initial development in composite B.
\end{abstract}

\section{Introduction}

A characteristics feature of the mid- and uppertropospheric flow is the continuous presence of synopticscale waves. These waves have an important role in both the heat and momentum budget, and can induce surface cyclogenesis. Following the Petterssen and Smebye (1971) study, the extratropical cyclones can be classified into types $\mathrm{A}$ or $\mathrm{B}$, depending on the configuration of the upper- and lower-level circulation. In type A, the surface cyclone initially develops in lower levels, and the upper-level trough develops during the evolution of the cyclone associated with temperature advection. In type B, the surface cyclogenesis happens when the preexisting upper-level trough is located over an area favorable to

Corresponding author address: Everson Dal Piva, Universidade Federal de Santa Maria, P.O. Box 5021, Santa Maria, RS 97110970, Brazil.

E-mail: everson.bento@gmail.com cyclogenesis, such as the presence of warm advection in lower levels.

In the 1980s, Radinovic (1986) proposed the existence of another cyclone development called type C, which would be associated with orographic effects, known as lee cyclogenesis. More recently, Plant et al. (2003) proposed another cyclone category, whose initial development is similar to type B, but with subsequent developments strongly dependent on latent heat release at midlevels. It can be noted that with the exception of type $\mathrm{A}$, all other cyclone categories have the upper-level trough as a precursor. Sanders $(1986,1988)$ suggested that all type-A cyclones should be classified as type B, because they form predominantly over the oceans where there is not enough upper-level information to observe the trough precursor.

Studies of South American cyclogenesis have shown that mid- and upper-level troughs are present in all cases analyzed by Gan and Rao (1996), Innocentini and Caetano Neto (1996), Marengo et al. (1997), Seluchi and 
Saulo (1998), Vera et al. (2002), and Funatsu et al. (2004). The synoptic conditions associated with South American cyclogenesis were studied by Seluchi (1995) in 54 cases from 1980 to 1984 . The results showed that the disturbance triggering the surface cyclogenesis can be identified 5 days before the surface cyclogenesis when a long-wave midtropospheric trough, over an area of enhanced baroclinicity near to $35^{\circ} \mathrm{S}$ is present.

Since the mid- and upper-level troughs are crucial for the development of surface cyclogenesis, several studies were made with the objective of identifying preferential areas of formation, dissipation, and displacement of the troughs in the Northern (Sanders 1988; Lefevre and Nielsen-Gammon 1995; Dean and Bosart 1996) and Southern (Keable et al. 2002; Fuenzalida et al. 2005; Piva et al. 2008a) Hemispheres.

The classic normal-mode baroclinic instability, the nonmodal instability, and the downstream development (DSD) are the main theories, or conceptual models used to explain the upper-level mobile trough genesis (NielsenGammon 1995). From a baroclinic view, the energy exchange happens between eddies and basic-state flow through the heat and momentum fluxes. Randel and Stanford $(1985 a, b)$ showed that the energy exchange between wave and steady-state flow is a valid concept in the Southern Hemisphere. Also, the medium-scale Rossby wave (with a wavenumber between 4 and 7) presented a well-defined life cycle, with baroclinic growth, maturity, and barotropic decay. However, the ageostrophic fluxes vanish because their calculations are integrated over a latitude belt encompassing all $360^{\circ}$ longitudes. Nonetheless, when we compute the energetics using a regional rather than a zonal average, it is possible to notice that the eddy kinetic energy (EKE) is transported downstream through the ageostrophic geopotential fluxes.

The mechanism associated with DSD is the wave energy dispersion. In the case of Rossby waves, the westerly group velocity results in a DSD sequence of the troughs and ridges show time and spatial scales that agree with the observed conditions. Studying the life cycle of the troughs in the Southern Hemisphere for the 1984-85 summer, Chang (2000) found that, except for the first wave, the majority of the waves that develop later are associated with wave packets dominated by ageostrophic energy fluxes and not by baroclinic-barotropic conversion. The DSD mechanism was also identified in the subtropical and polar jets in the Southern Hemisphere, particularly in the first one because of the smaller baroclinicity (Berbery and Vera 1996; Rao et al. 2002).

The downstream baroclinic development (DSBD) proposed by Orlanski and Sheldon (1995) associates the DSD to baroclinic instability. In this theory, the initial EKE growth occurs by ageostrophic flux convergence and is maintained by baroclinic conversion. They suggest is that the eddy generated by upper-level ageostrophic fluxes can induce circulation at lower levels, allowing the eddy to use the baroclinicity available locally.

South America near $35^{\circ} \mathrm{S}$ is an important region for surface cyclogenesis (Gan and Rao 1991; Sinclair 1994, 1995; Simmonds and Keay 2000). This region becomes more prominent if only the more intense systems are considered (Sinclair 1995). These intense systems can lead to explosive cyclogenesis as a theme of increasing interest (Seluchi and Saulo 1998; Piva et al. 2008b). Despite this, the energetics of the surface cyclogenesis in this region still have not been studied. In other regions of the world, the extratropical cyclone kinetic energy budget has been the subject of several studies (Eddy 1965; Smith 1973; Chen and Bosart 1977; Kung 1977; Smith 1980; Dare and Smith 1984; Masters and Kung 1986; Lackmann et al. 1999; Decker and Martin 2005; Danielson et al. 2006a,b), using different datasets and methodologies. Most of them considered the ageostrophic flux convergence and the baroclinic conversion (vertical velocity and temperature correlation) terms in the same mechanism called cross-isobaric flow (a good discussion about this can be found in Orlanski and Katzfey 1991). As a consequence, the DSD is not emphasized. The studies that considered both terms separately (emphasizing the DSD) were applied to kinetic energy budget of the upperlevel troughs (Orlanski and Katzfey 1991; Orlanski and Sheldon 1993; Chang 2000) and no attention was given to surface cyclones.

Therefore, the kinetic energy budget applied to the coupled trough-cyclone system, emphasizing the energy transport due to ageostrophic fluxes in the cyclogenesis cases over South America have not been studied yet, and this is the objective of this article.

\section{Data and methodology}

The datasets used were the 6-hourly gridded data from the National Centers for Environmental PredictionNational Center for Atmospheric Research (NCEPNCAR) reanalysis (Kalnay et al. 1996) for the 1999-2003 winters. The intercomparison between the NCEP-NCAR and NCEP-Department of Energy (DOE) reanalysis showed that the latter is more active (considering the track density and mean intensity) in the South Hemisphere storm track region than the first one, mainly in the cyclonic relative vorticity at $850 \mathrm{mb}$ and in the mean sea level pressure (SLP) field (Hodges et al. 2003). The intercomparison between the NCEP-NCAR and the 40-yr European Centre for Medium-Range Weather Forecasts (ECMWF) Re-Analysis (ERA-40) showed that the latter presents greater strong-cyclone activity 
and less weak-cyclone activity over most areas of the austral extratropical ocean than the NCEP-NCAR (Wang et al. 2006). Opposite trends in the mean SLP cyclone frequency were identified in previous studies. In the NCEP-NCAR and NCEP-DOE datasets the trends were negative (Simmonds and Keay 2000; Lim 2005), but in the ERA-40 the trends were positive (Lim and Simmonds 2007). The comparison of annual mean atmospheric energetics was carried out with NCEPNCAR and ERA-40 by Marques et al. (2009). No appreciable difference was found between the two reanalyses, although the energetics from NCEP-NCAR was, in general, slightly smaller than those from ERA-40. Such small differences were found mainly in the South Hemisphere. Thus, some differences between our results and other studies using another reanalysis dataset can be expected. Based on the previous studies, it seems that the energy conversions terms may be more intense in the ERA-40 than in the NCEP-DOE dataset; and more intense in the latter than in the NCEP-NCAR dataset.

Only the winter (June-August) was considered when selecting the cases because this season has the highest frequency of surface cyclogenesis over Uruguay and adjacent areas (area between $60^{\circ}-45^{\circ} \mathrm{W}$ longitude and $37.5^{\circ}-27.5^{\circ} \mathrm{S}$ latitude, represented by the box over the east coast of South America in Fig. 2) according to published studies (Gan and Rao 1991; Sinclair 1994, 1995). Another reason for this choice was to avoid features absent in winter but present in the other seasons (such as the Bolivian high or diurnal convection over southeast Brazil), which disturb the composites. Only $5 \mathrm{yr}$ were considered because there were enough cases to make the composites during this period. All the situations with a midtropospheric $(500 \mathrm{hPa})$ trough that generated surface cyclogenesis were analyzed, and the center of the surface cyclone was located over Uruguay and adjacent areas. Thus, we did not consider situations such as (i) when the midtropospheric troughs were very weak, which induced just a light reduction of sea level pressure; or (ii) when midtropospheric troughs generated a surface cyclone in an area very far from the area of interest (e.g., near the Andes or south of $40^{\circ} \mathrm{S}$ ). Based on these criteria, 38 cases were separated in two composites indicated as B (with 25 cases) and C (with 13 cases). Letters $B$ and $C$ were chosen because the synoptic characteristics of the cases are similar to the type-B cyclone according to the Petterssen and Smebye (1971) and type-C cyclone following the Radinovic (1986) criteria, respectively. Composite $\mathrm{C}$ had three characteristics of the type-C cyclone: (i) a preexistent surface cyclone over the southeast Pacific Ocean, (ii) a cold air block west of the Andes, and (iii) the southward incursion of warm air over South America east of the Andes. The cyclones with different characteristics were grouped in composite B. Although the separation of cases into B and $\mathrm{C}$ composites would appear to be qualitative and somewhat subjective, it should be emphasized that the categorization was based on the experience and regional knowledge of the authors. Results in papers published by other authors (Seluchi 1995; Innocentini and Caetano Neto 1996; Funatsu et al. 2004; Mendes et al. 2007) were also considered. The cyclone was considered formed when there was a closed isobar in the sea level pressure field with a 2-hPa contour interval, as used by Gan and Rao (1991). The semistationary and persistent closed pressure centers over Paraguay and northwestern Argentina were not considered because they are not transient systems. The midtropospheric troughs were defined with the association of the 3 variables at $500 \mathrm{hPa}$ : (i) the geopotential height every $60 \mathrm{~m}$, (ii) the Eulerian centripetal acceleration (proposed by Lefevre and Nielsen-Gammon 1995), and (iii) the meridional wind component. The lifetime of the trough began when the geopotential height presented cyclonic curvature, and the Eulerian centripetal acceleration became positive. During the trough development, the Eulerian centripetal acceleration and the geopotential cyclonic curvature increased (both in area and magnitude). The zero isoline of the meridional wind component placed on the maximum of the Eulerian centripetal acceleration made the trough identification and tracking easier.

The wavelength and amplitude of the troughs were obtained from the Hovmöller diagram of geopotential height deviation averaged in the latitudinal belt. The geopotential height deviation was calculated subtracting the geopotential height zonal mean, and averaging this value over the $30^{\circ}-40^{\circ} \mathrm{S}$ latitude belt for most of the cases. The trough wavelength corresponds to the distance (in degrees longitude) between two isolines with zero deviation, one west of the trough and the other east of the downstream ridge. The trough meridional tilt was determined from the horizontal tilt of the null meridional wind component isoline.

The trough energetics was calculated by the EKE equation (Orlanski and Katzfey 1991):

$$
\begin{aligned}
\frac{\partial K}{\partial t}= & -\boldsymbol{\nabla} \cdot(\mathbf{V} K)-\boldsymbol{\nabla} \cdot\left(\mathbf{V}_{a}^{\prime} \phi^{\prime}\right)-\omega^{\prime} \alpha^{\prime}-\mathbf{V}^{\prime} \cdot\left(\mathbf{V}_{3}^{\prime} \cdot \nabla_{3}\right) \overline{\mathbf{V}} \\
& +\mathbf{V}^{\prime} \cdot \overline{\left(\mathbf{V}_{3}{ }^{\prime} \cdot \nabla_{3}\right) \mathbf{V}^{\prime}}-\frac{\partial \omega K}{\partial p}-\frac{\partial \omega^{\prime} \phi^{\prime}}{\partial p}+\text { RES. }
\end{aligned}
$$

Here, $K$ is the EKE per unit mass, $\mathbf{V}$ is the horizontal wind velocity, $\omega$ is the vertical velocity in pressure coordinates, $\phi$ is the geopotential, $\alpha$ is the specific volume, and $p$ is the pressure. The overbar denotes time mean 
and primed quantities denote deviation from time mean, which include the months of June, July, and August (as used by Lackmann et al. 1999; Chang 2000). The vectors and gradient operators with the subscript " 3 " represent three-dimensional vectors, while those without the subscript contain the horizontal components only. The subscript $a$ represents the horizontal ageostrophic wind components with most of the nondivergent part removed by defining the geostrophic wind with a constant Coriolis parameter (Orlanski and Sheldon 1993).

The meaning of the right-hand terms of Eq. (1) was discussed by Orlanski and Katzfey (1991) and Chang (2000). The first term is called EKE flux convergence (KFC) and represents the advective energy flux. It is responsible for displacing the EKE maximum. The second term is the ageostrophic flux convergence (AFC), which represents the radiative energy transport, and is associated with the dispersive nature of the waves. The third term represents the baroclinic (BRC) conversion. The fourth and fifth terms represent Reynolds and mean stresses, respectively, and, since they are associated with horizontal shear, they might be regarded as barotropic (BRT) conversion. The sixth and seventh terms are the vertical advection and energy flux, respectively. The last term is the budget residue (RES) that is obtained from the difference between observed kinetic energy tendency (OKT) and calculated kinetic energy tendency
(CKT). The OKT is obtained by the difference of the two EKE field with a 12-h interval and the CKT is the sum of all terms on the right-hand side of Eq. (1), except for the RES term. So, the RES contains mechanisms that are not explained by Eq. (1), such as the friction, diabatic, and subgrid effects; besides errors due to the numerical methods such as the interpolation and taking derivatives.

The terms in the EKE tendency equation are presented in the vertically averaged form, which is defined as

$$
A=\frac{1}{\left(P_{B}-P_{T}\right)} \int_{P_{T}}^{P_{B}} a d p .
$$

Here $A$ is the vertically averaged variable, $a$ is the variable given in several pressure levels, and $P_{T}$ is the pressure at the top $(100 \mathrm{mb})$ of the data. At the bottom $\left(P_{B}\right)$, the pressure depends on the orography that was obtained by reanalysis data. However, the lowest level was the $1000-\mathrm{hPa}$ pressure surface.

The advantage of Eq. (1) is that it contains the three dominant processes of trough formation and dissipation, such as the baroclinic instability (BRC term), the barotropic instability (BRT term) and the DSD (AFC term). This equation can be integrated over a volume, resulting in Eq. (2) (Chang 2000):

$$
\begin{aligned}
\frac{\partial\langle K\rangle}{\partial t}= & -\langle\nabla \cdot(\mathbf{V} K)\rangle-\left\langle\nabla \cdot\left(\mathbf{V}_{a}^{\prime} \phi^{\prime}\right)\right\rangle-\left\langle\omega^{\prime} \alpha^{\prime}\right\rangle-\left\langle\mathbf{V}^{\prime} \cdot\left(\mathbf{V}_{3}^{\prime} \cdot \nabla_{3}\right) \overline{\mathbf{V}}+\mathbf{V}^{\prime} \cdot \overline{\left(\mathbf{V}_{3}^{\prime} \cdot \nabla_{3}\right) \mathbf{V}^{\prime}}\right\rangle-\left.[\omega K]\right|_{B} \\
& +\left.[\omega K]\right|_{T}+\left.\left[\omega^{\prime} \phi^{\prime}\right]\right|_{B}+\left.\left[\omega^{\prime} \phi^{\prime}\right]\right|_{T}+\langle\mathrm{RES}\rangle+\left\langle\boldsymbol{\nabla} \cdot \mathbf{V}_{v} K\right\rangle+\left.\left[\left(\frac{\partial p_{s}}{\partial t}+\mathbf{V}_{v} \cdot \nabla p_{s}\right) K\right]\right|_{B}
\end{aligned}
$$

Here, the \langle\rangle and [] symbols represent the volume and surface integral, respectively. The last symbol can be at the top (subscript $T$, taken at the $100-\mathrm{hPa}$ level) or at the bottom (subscript $B$, taken at the surface pressure) of the volume. The subscripts $v$ and $s$ represent the velocity of the volume and the surface level, respectively.

The terms of Eq. (2) have the same interpretation as those in Eq. (1), except for the two vertical transport terms in Eq. (1) (sixth and seventh terms) that were transformed into a surface integral and can be interpreted as the vertical energy fluxes through the lower [bottom (B)] and upper [top ( $\mathrm{T})$ ] boundaries (from sixth to ninth terms). The tenth term represents the energy flux due to the volume integration displacement, while the last term represents the change of energy due to the variation of the mass in the volume. Here, the volume is kept fixed, so, the terms (tenth and part of the last term), which involve the volume displacement, vanish.
Equation (2) requires the setting of the volume dimensions. (For both composites, the area used is represented by dashed lines in Figs. 7a and 12a.) The latitudinal boundaries are from $50^{\circ}$ to $20^{\circ} \mathrm{S}$, and $30^{\circ}$ wide longitude. In the vertical the levels from the surface to $100 \mathrm{hPa}$ were used. Over high orography areas, the integration at lower levels depends on the mountain height given by reanalysis data. The volume-averaged approach introduces complications arising from the need to define a volume of integration. Boundary flux terms and more than one feature within the control volume are some examples. Further discussions about this can be found in McGinley (1982), Dare and Smith (1984), and Lackmann et al. (1999).

\section{Results}

Figure 1 shows some characteristics of the midtropospheric $(500 \mathrm{hPa})$ troughs of composites $\mathrm{B}$ and $\mathrm{C}$, 


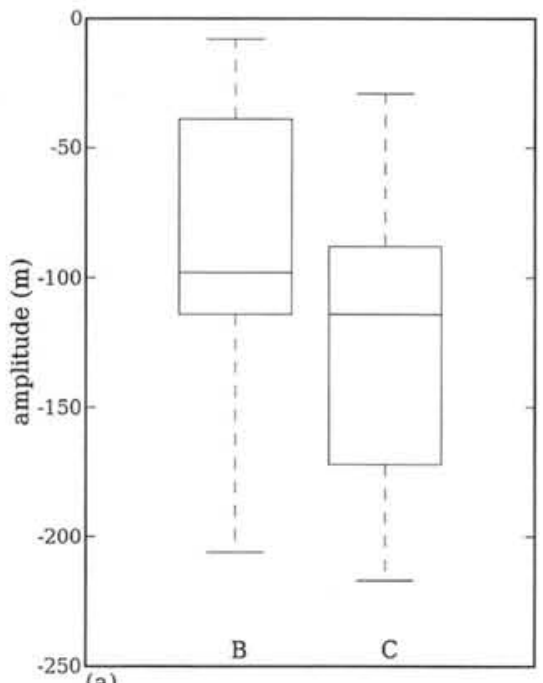

(a)

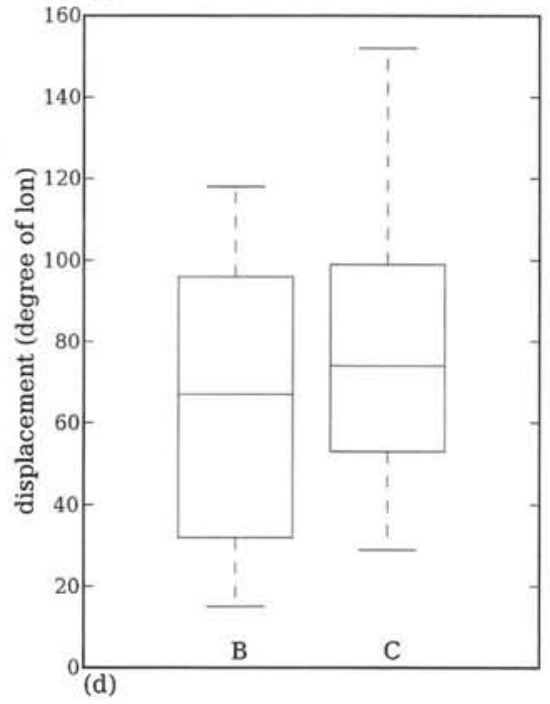

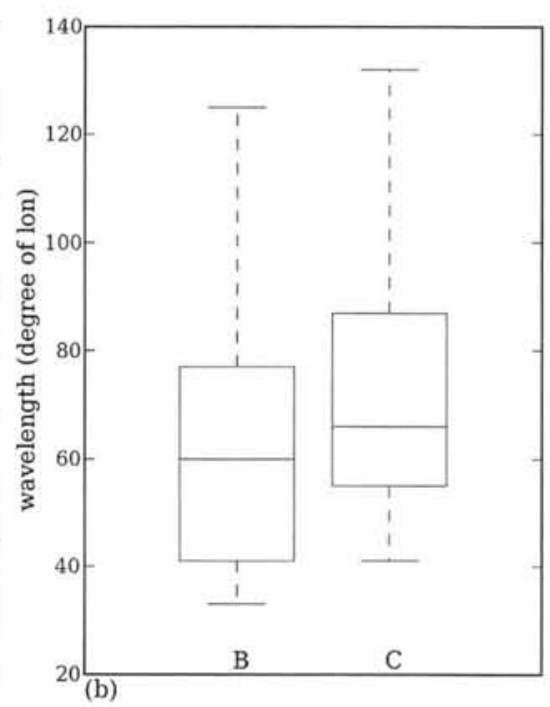
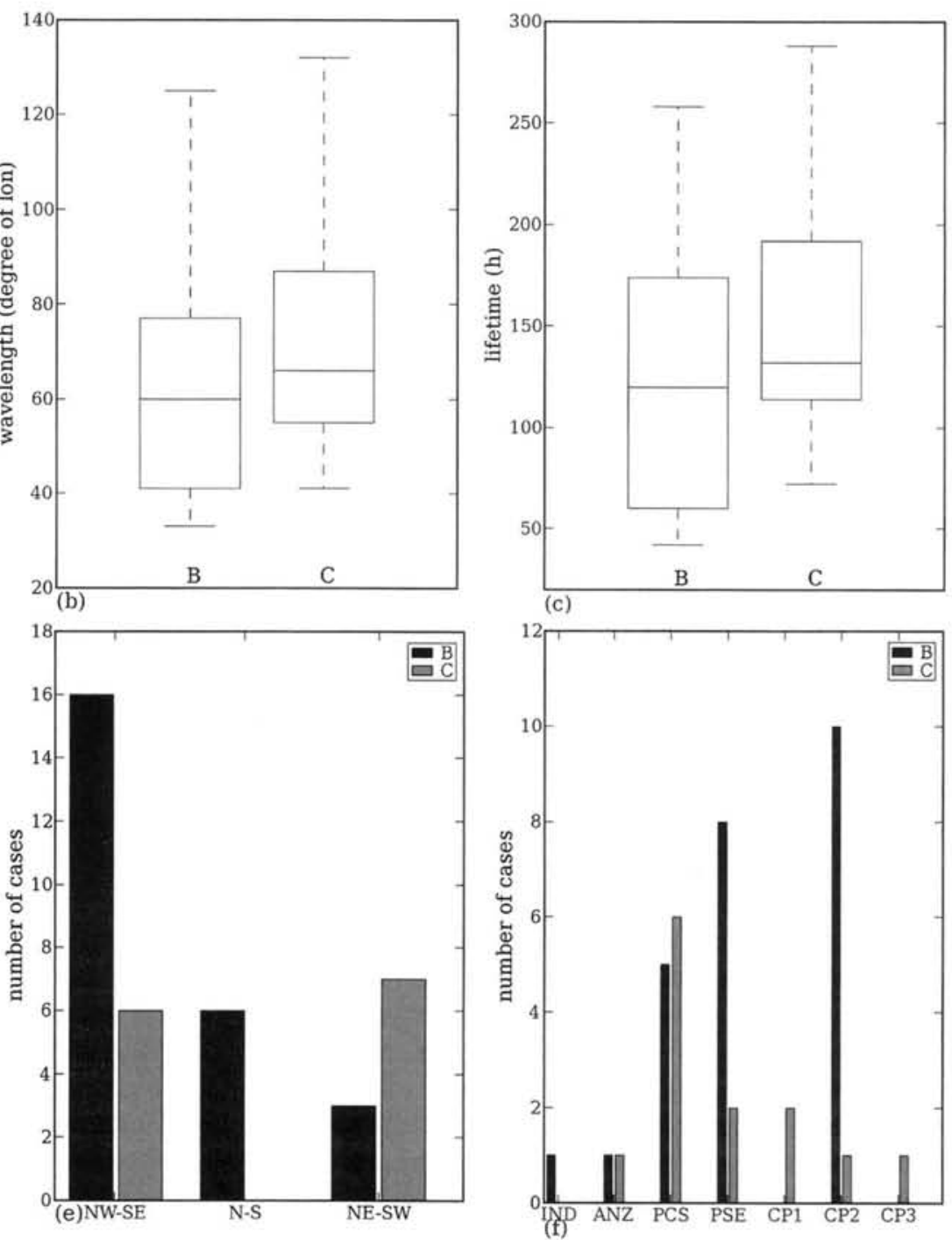

FIG. 1. Trough characteristics for the composites B and C: (a) amplitude (m), (b) wavelength ( ${ }^{\circ}$ lon), (c) lifetime (h), (d) displacement $\left({ }^{\circ}\right.$ lon), (e) meridional tilting during cyclone formation time, and (f) genesis area as indicated in Fig. 2.

respectively. The trough amplitude ranged from -206 $(-217) \mathrm{m}$ to $-8(-29) \mathrm{m}$ and the amplitude average was $-88(-118) \mathrm{m}$ for composite $\mathrm{B}(\mathrm{C})$, indicating that the troughs in composite $\mathrm{C}$ might be more intense than in the case of B (Fig. 1a). The difference in the amplitude between the composites is statistically significant at the level of $90 \%$ (according to the Student's $t$ test). The average wavelength was $64^{\circ}$ longitude (wavenumber $K=5-6)$ and $76^{\circ}$ longitude $(K=4-5)$ for composites B and $\mathrm{C}$, respectively (Fig. 1b). The average lifetime was $128 \mathrm{~h}(160 \mathrm{~h})$ and the traveled distance was $69^{\circ}\left(81^{\circ}\right)$ longitude for composite-B (-C) troughs (Figs. 1c,d). The meridional tilt of the troughs was northwest-southeast (or positive tilt) for most of the troughs in composite B and northeast-southwest (or negative tilt), followed by northwest-southeast in composite C (Fig. 1e). This indicates poleward and equatorward eddy momentum transport for composites B and C, respectively (Holton 1992, p. 336). Many composite-C troughs are formed in remote regions of South America, as shown in Figs. If and 2 . Figure 1 shows that there is a wide variety of trough configurations that generate cyclones in South America. In this figure, we can see composite- $\mathrm{C}$ troughs are more intense, have a longer wavelength, and that their genesis is more distant from South America.

Figures 3 and 4 show the SLP and 500-hPa geopotential height for composites $\mathrm{B}$ and $\mathrm{C}$, respectively. Initially we observed that there is a small-scale trough with north-south horizontal tilt at $80^{\circ} \mathrm{W}$ (Fig. 3a). The southern part of the trough, south of $30^{\circ} \mathrm{S}$, moves east at 


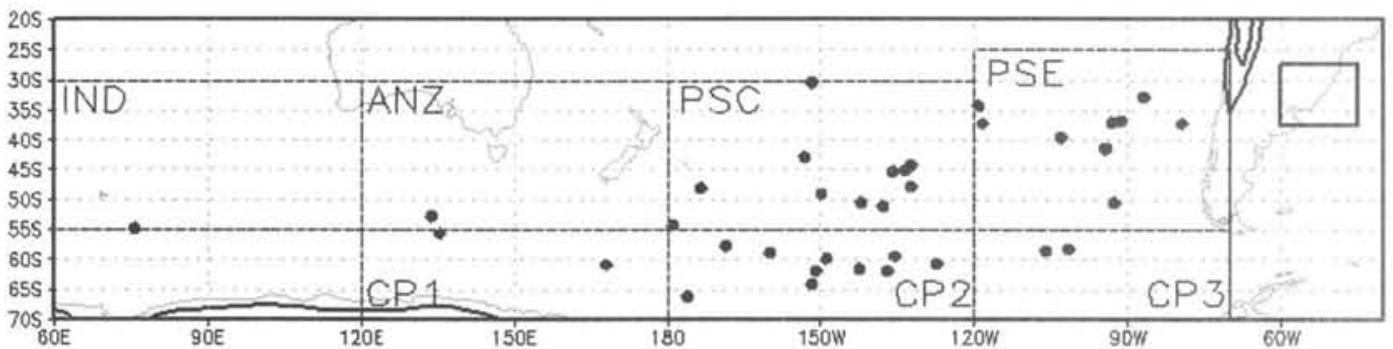

FIG. 2. Positions of trough formation for composites B and C. Genesis areas are the Indian Ocean (IND), AustraliaNew Zealand (ANZ), Pacific South Center (PSC), Pacific Southeast (PSE), and Circumpolar 1, 2, and 3 (CP1, CP2, and CP3), respectively. The box over the east coast of South America indicates the region where the surface cyclones must be stationed to be considered in the composites. Topography ( $\mathrm{km}$, thick isoline, label omitted) over South America corresponds to $1.5,3$, and $4.5 \mathrm{~km}$.

the same time its amplitude increases and changes its meridional tilt to northwest-southeast (Figs. 3b-d). At $0 \mathrm{~h}$, the formation of the surface cyclone, whose center is identified in Fig. 3c with a closed isobar, occurs. After $24 \mathrm{~h}$, an indication of trough division is observed, with the presence of two troughs, one with a strong northwestsoutheast meridional tilt with axis passing through $30^{\circ} \mathrm{S}$, $75^{\circ} \mathrm{W}$ and another with northeast-southwest tilt over the South Atlantic Ocean. The SLP field for composite B shows two subtropical anticyclones, one over the South
Pacific Ocean and another over the South Atlantic, plus a region of low pressure over South America (Fig. 3a). At $-24 \mathrm{~h}$, there was an inverted trough structure over Paraguay, northern Argentina, and southern Brazil (Fig. 3b). This surface trough extends southeast for the following $24 \mathrm{~h}$, when the formation of the surface cyclone over Uruguay with central pressure of $1012 \mathrm{hPa}$ occurs (Fig. 3c). The cyclone intensifies and moves southeast with a central pressure of $1008 \mathrm{hPa}$ at $+24 \mathrm{~h}$ (Fig. 3d). Figure 3 also shows the intensification of subtropical anticyclones over
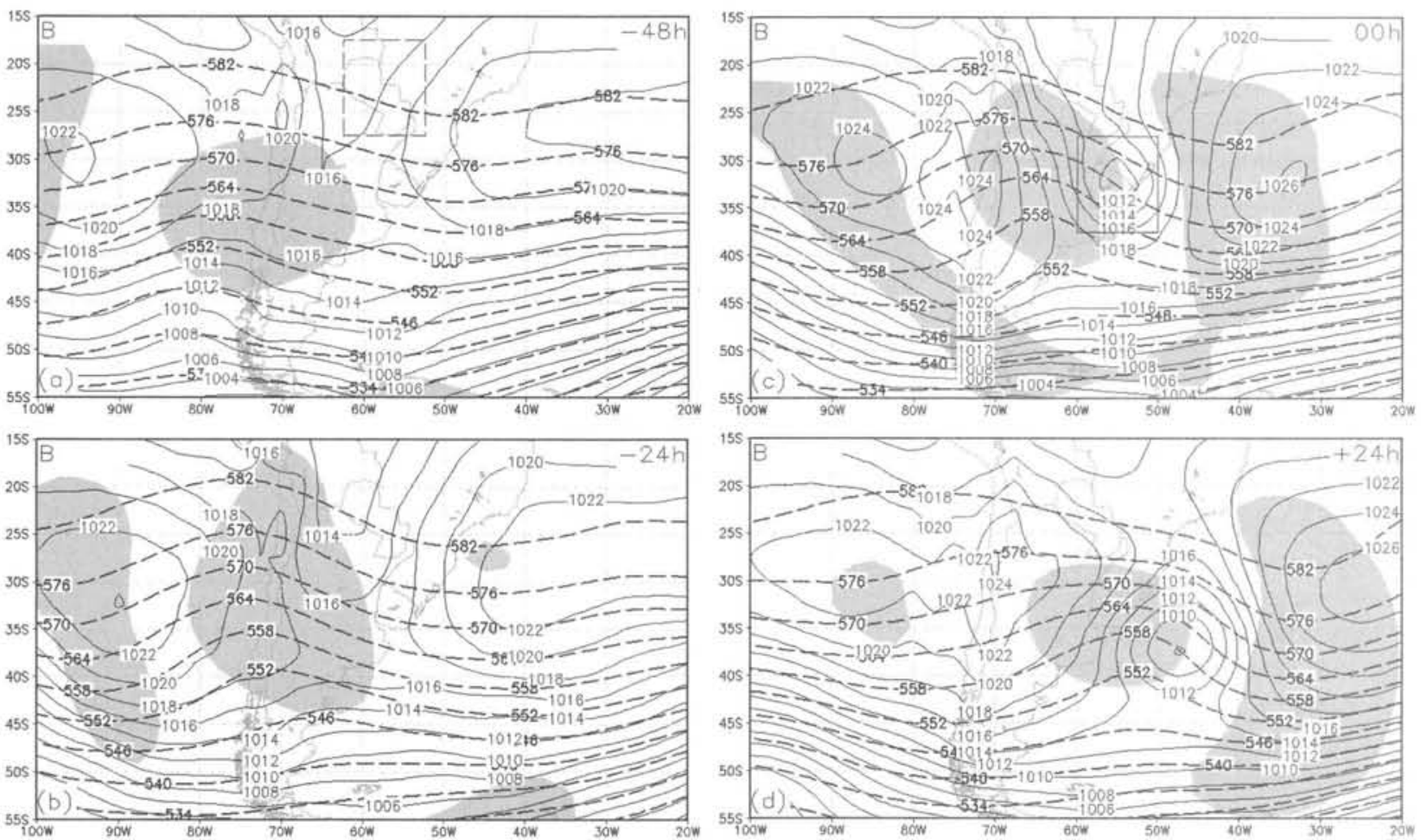

FIG. 3. (a)-(d) SLP [solid line, contour interval (CI) $2 \mathrm{hPa}$ ] and 500-hPa geopotential height (dashed line, $\mathrm{Cl} 6$ dam, shaded regions are statistically significant at level of $95 \%$ ) of composite B. In (a), the box with dashed lines indicates the area where the spatial average of the heat and moisture flux shown in Fig. $5 \mathrm{c}$ were made. In (c), the box with solid lines shows the area where the spatial average of the variables shown in Figs. 5a,b and 6 were made. The time in the upper-right corners refers to the formation of the surface cyclone. 

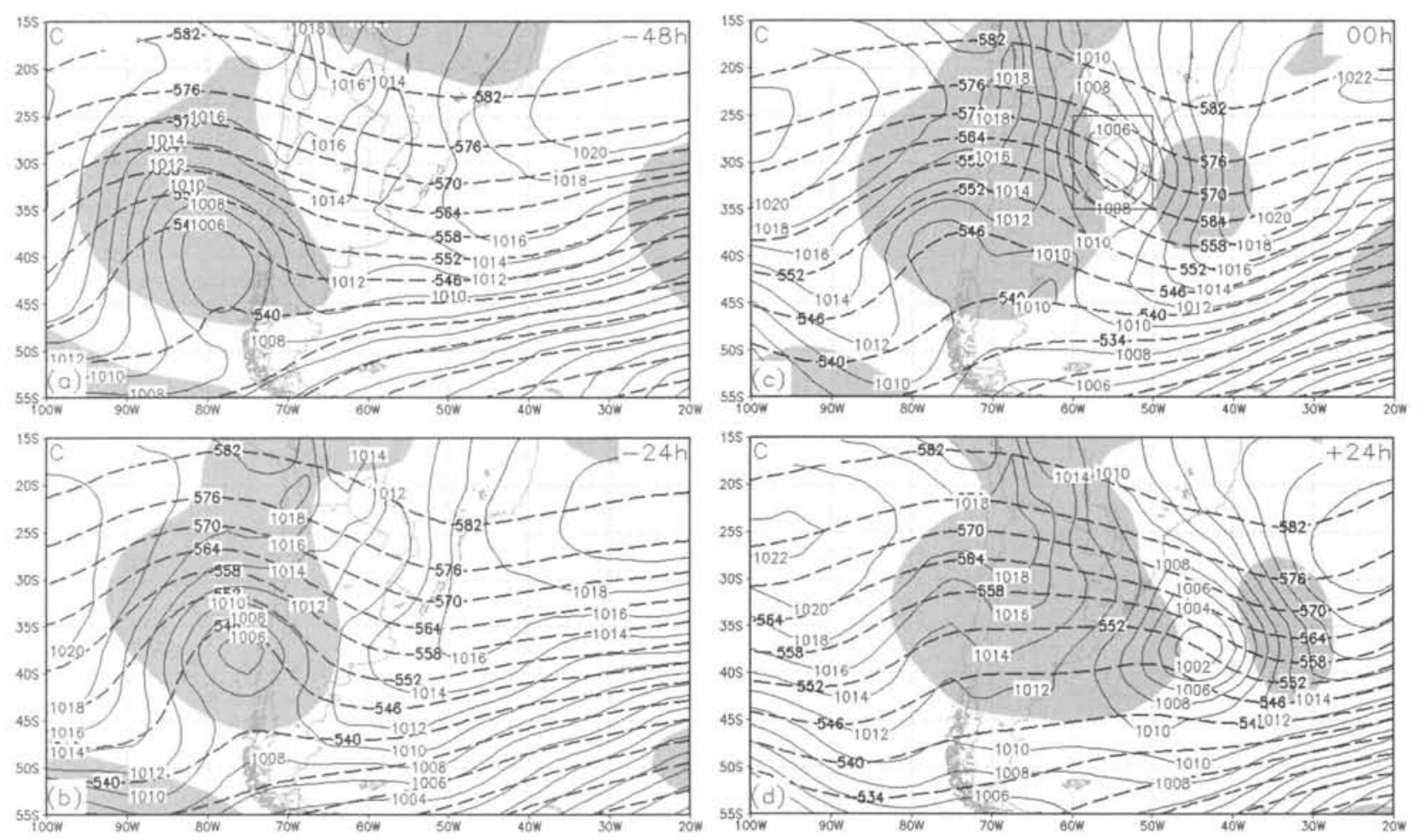

FIG. 4. As in Fig. 3, but for composite C.

the oceans and the intrusion of a transient anticyclone over the South American continent, even though the transient anticyclone is not well defined.

The geopotential height evolution for composite C confirms that the trough had higher amplitude and wavelength than in composite B (Fig. 4). This result is expected, since the cases chosen for composite $\mathrm{C}$ had a preexisting surface cyclone over the Pacific Ocean (from -48 to -12 h) as observed in Figs. $4 a$,b. At midlevels the trough moves toward South America and becomes less defined than in composite B. At $+24 \mathrm{~h}$ there is an indication of two troughs, one over the Andes and another short wave over southeastern Brazil and the South Atlantic Ocean (Fig. 4d). Two processes might explain the presence of the two troughs. One is the trough division that happened in composite $\mathrm{B}$, while the other is linked to the fact that some cyclones over the Southeastern Pacific maintain their structures for a longer period. This keeps the trough over the region while the other trough continues its propagation. The SLP composite C (Fig. 4) shows that at $-48 \mathrm{~h}$ there was a cyclone in the southeastern Pacific Ocean, an anticyclone over the South Atlantic Ocean, and an area of low pressure over South America (Fig. 4a). The cyclone over the South Pacific moves to north, reducing its horizontal scale and weakening until it disappears at 0 h (Figs. $4 \mathrm{a}-\mathrm{c}$ ). The transient cyclone develops at $0 \mathrm{~h}$ over southern
Brazil and Uruguay with 1006-hPa central pressure (Fig. 4c). The cyclone that formed over southern Brazil and Uruguay moves southeast and becomes more intense, reaching a central pressure of $1002 \mathrm{hPa}$ after $24 \mathrm{~h}$ (Figs. 4c,d). The dissipation of the surface cyclone over the southeast Pacific and the formation of a new cyclone to the northeast of the preexisting one over South America is a typical feature of lee cyclogenesis (Buzzi and Tibaldi 1978; McGinley 1982; Gan and Rao 1994).

The variation of the geopotential height and the SLP fields in composite B (Fig. 3) and C (Fig. 4) show a typical pattern of cyclone occurrence of type B and type C, respectively, usually observed over Uruguay and adjacent areas.

The surface cold front present in both composites has a different behavior in each case. In composite B, the cold front shows a rapid displacement to the northeast (Fig. 3c) over southern Brazil, with a meridional extension around $48^{\circ} \mathrm{W}$ at $+24 \mathrm{~h}$ (Fig. $3 \mathrm{~d}$ ). In composite C, the cold front shows a slow movement (Fig. 4c) and extension to the northwest from the South Atlantic Ocean $\left(35^{\circ} \mathrm{S}\right.$, $45^{\circ} \mathrm{W}$ ) to Paraguay around $20^{\circ} \mathrm{S}, 55^{\circ} \mathrm{W}$ (Fig. $4 \mathrm{~d}$ ). Another difference between the two composites refers to the surface winds within the warm sector of the cyclone during the period from -12 to $0 \mathrm{~h}$ (Figs. $3 \mathrm{c}$ and $4 \mathrm{c}$ ). Based on SLP fields, we can deduce that in composite B the flow 

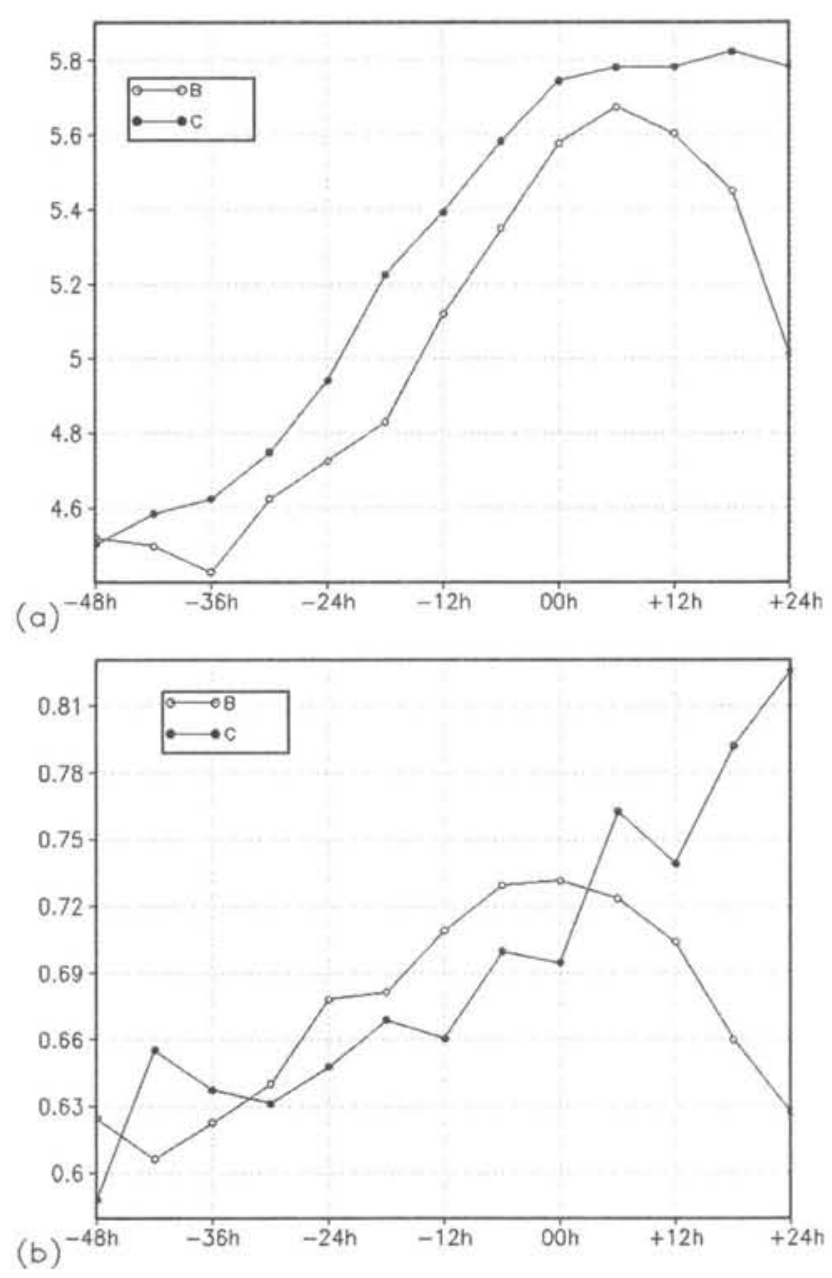

is northerly with a small zonal component (Fig. 3c), while in composite $\mathrm{C}$ the flow is northwesterly (Fig. 4c). These differences are linked to the fact that in composite $\mathrm{C}$, the surface cyclone forms farther north than in composite B, and is directly related to the transport of heat and moisture from the Amazon region toward the cyclone.

The time evolution of some variables averaged in the area is shown in Fig. 5. The temperature gradient and the Eady growth rate were calculated in the area indicated in Fig. 3c (composite B) and Fig. 4c (composite C). The area used for the calculation of the meridional equivalent potential temperature flux in the two composites is indicated in Fig. 3a. The horizontal temperature gradient shows the same behavior for both composites, but for composite $\mathrm{C}$ the gradient is slightly higher (Fig. 5a). The temperature gradient increases from $4.5^{\circ} \mathrm{C}(500 \mathrm{~km})^{-1}$ at $-48 \mathrm{~h}$ to $5.6^{\circ} \mathrm{C}(500 \mathrm{~km})^{-1}$ in composite $\mathrm{B}$, and to $5.8^{\circ} \mathrm{C}(500 \mathrm{~km})^{-1}$ in composite $\mathrm{C}$ at $0 \mathrm{~h}$ (surface cyclone formation time). The larger difference between these composites is found at the end of the period (from +6 to $+24 \mathrm{~h}$ ), when the temperature

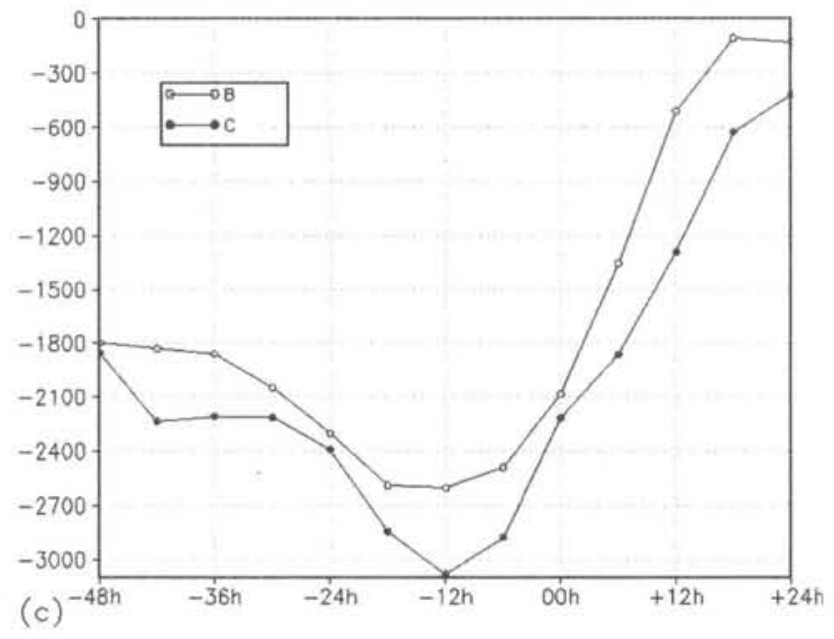

FIG. 5. Spatial average for the (a) horizontal temperature gradient $\left[{ }^{\circ} \mathrm{C}(500 \mathrm{~km})^{-1}\right]$, (b) Eady growth rate $\left(\right.$ day $\left.^{-1}\right)$, and (c) meridional equivalent potential temperature flux $\left(\mathrm{K} \mathrm{m} \mathrm{s}^{-1}\right)$ for composites B (open circle) and C (closed circle) at $850 \mathrm{hPa}$.

gradient decreases rapidly in composite B; however, in composite $\mathrm{C}$ the temperature gradient remains constant. This difference also appears in the Eady growth rate. Until the formation of the cyclone $(0 \mathrm{~h})$, the growth rate remains practically the same in both composites. There is an increase until $0 \mathrm{~h}$, after that there is a decrease in composite $\mathrm{B}$, while the increase in composite $\mathrm{C}$ continues (Fig. 5b). This behavior might be associated to the surface cold front, because in composite C (Figs. 4c,d) the front moves more slowly northeast than in composite B (Figs. 3c,d). Unlike the temperature gradient, the Eady growth rate in composite $\mathrm{B}$ was slightly higher than in composite $\mathrm{C}$ for the period from -30 to $+3 \mathrm{~h}$. This appears to be a contradictory result because of the geostrophic relationship between the horizontal temperature gradient and vertical wind shear. However, this is explained by the fact that we used the more general form as given in Simmonds and Lim (2009). The explanation for this contradiction may be due to the fact that in addition to thermal wind, the Eady growth rate involves static stability through the Brunt-Väisälä frequency. However, 

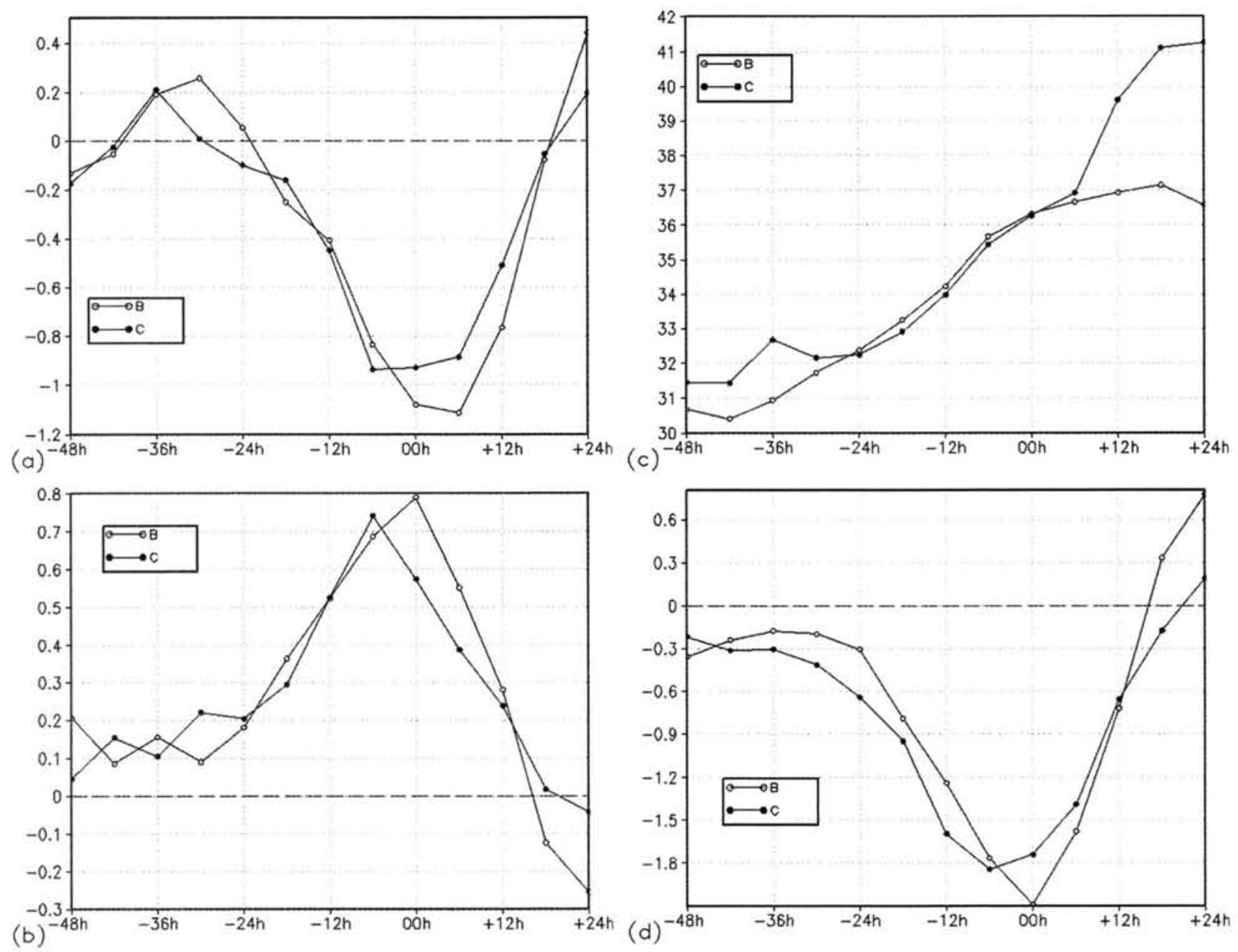

FIG. 6. As in Fig. 5, but for (a) relative vorticity advection $\left(\times 10^{-9} \mathrm{~s}^{-2}\right)$, (b) divergence $\left(\times 10^{-5} \mathrm{~s}^{-1}\right)$, (c) wind magnitude (m s$\left.)^{-1}\right)$ at $300 \mathrm{hPa}$, and (d) vertical velocity $\left(\times 10 \mathrm{~Pa} \mathrm{~s}^{-1}\right)$ at $500 \mathrm{hPa}$.

thermal stability does not seem to explain this contradiction, because, as shown in Fig. $5 \mathrm{c}$, the meridional heat and moisture flow from the Amazon region is greater in composite $\mathrm{C}$ than in composite $\mathrm{B}$, suggesting that the thermal stability is smaller in composite $\mathrm{C}$ than in composite $\mathrm{B}$. The warm and wet air transport toward the south of the continent reaches its maximum at $-12 \mathrm{~h}$, suggesting that this transport is important for cyclogenesis preconditioning (Mendes et al. 2007). This agrees with the formation mechanism of the type-B and type-C cyclone, in which an upper-level trough is necessary over the warm advection region (Petterssen and Smebye 1971; Radinovic 1986).

The evolution of the relative vorticity advection, divergence, wind speed at $300 \mathrm{hPa}$, and vertical velocity at $500 \mathrm{hPa}$ in composites $\mathrm{B}$ and $\mathrm{C}$ are shown in Fig. 6 . The relative vorticity advection shows negative values for approximately $24 \mathrm{~h}$ before the surface cyclogenesis (between -24 and $0 \mathrm{~h}$ ). This confirms the importance of troughs at high levels during the cyclone formation period, as separated for type-B and type-C cyclones (Fig. 6a). We can see this in the divergence (Fig. 6b) and vertical velocity (Fig. 6d) fields, which display the increase of the divergence and upward vertical motion until the cyclogenesis starts in composite B (at $0 \mathrm{~h}$ ) or until $6 \mathrm{~h}$ before the cyclogenesis in composite $\mathrm{C}(-6 \mathrm{~h})$. We can see that the wind magnitude presents almost the same behavior in both composites until $+6 \mathrm{~h}$. Up to this time the wind remains constant in composite $\mathrm{B}$, around $37 \mathrm{~m} \mathrm{~s}^{-1}$, but continues to intensify in composite $\mathrm{C}$ until it reaches $40 \mathrm{~m} \mathrm{~s}^{-1}$. The analysis of the wind field at high levels is important because it is a source of kinetic energy for the development of both cyclone types as indicated by Radinovic (1986). In type-B cyclones, the energy is advected into the cyclone domain, mainly in the jet stream region, while in type $\mathrm{C}$, the energy increases by baroclinic conversion through the decrease in local baroclinicity and the redistribution of the kinetic energy of the zonal flow (Radinovic 1986). 

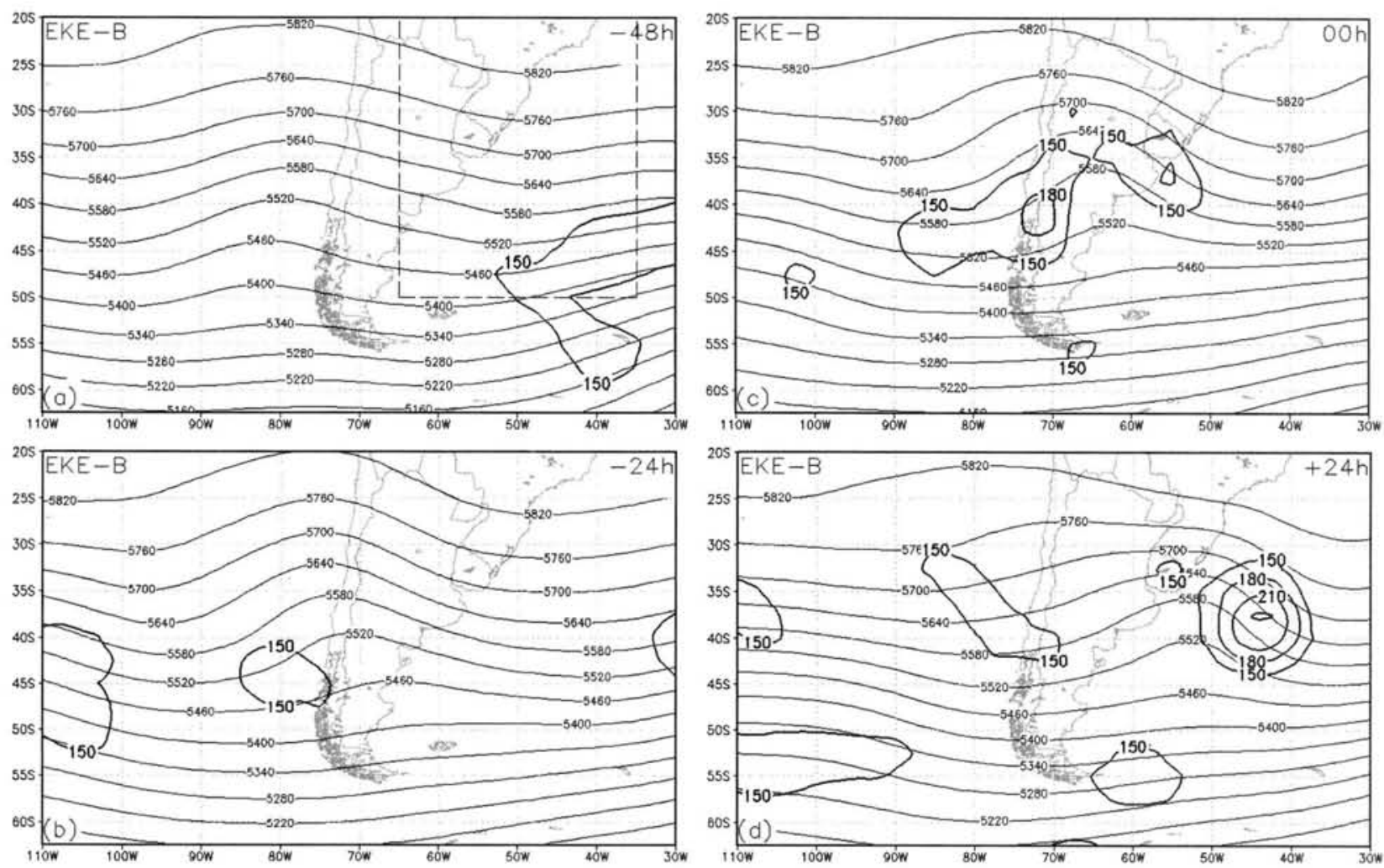

FIG. 7. (a)-(d) 500-hPa geopotential heights (CI $60 \mathrm{~m}$ ) and vertically averaged EKE (CI $30 \mathrm{~m}^{2} \mathrm{~s}^{-2}$, values below $150 \mathrm{~m}^{2} \mathrm{~s}^{-2}$ omitted) for composite B. In (a), the box with dashed lines represents the area where the volume average shown in Fig. 11 were made.

\section{Kinetic energy budget of composites}

\section{a. Composite B}

The evolution of both geopotential height at $500 \mathrm{hPa}$ and vertically averaged EKE are shown in Fig. 7. At the beginning $(-48 \mathrm{~h})$, EKE was around $150 \mathrm{~m}^{2} \mathrm{~s}^{-2}$ over the South Atlantic Ocean (Fig. 7a). The energy of the center upstream of the trough started to increase after $-36 \mathrm{~h}$, reaching the maximum of $180 \mathrm{~m}^{2} \mathrm{~s}^{-2}$ over the Andes at $0 \mathrm{~h}$ (Figs. $7 \mathrm{~b}, \mathrm{c}$ ). The energy center downstream of the trough reached the value of $150 \mathrm{~m}^{2} \mathrm{~s}^{-2}$ at $-12 \mathrm{~h}$ over South America, with the maximum of $240 \mathrm{~m}^{2} \mathrm{~s}^{-2}$ over the South Atlantic Ocean at $24 \mathrm{~h}$ (Figs. 7c,d). In energy conversion terms the emphasis will be given on the growth and decay phase of the maximum EKE centers west and east of the trough.

The BRC term (Fig. 8) is positive in almost over the entire domain except in an area close to the Andes (approximately $70^{\circ} \mathrm{W}$ at $-24 \mathrm{~h}$ ). Associated with the EKE maximum center upstream of the trough, there is an area of BRC conversion on the southeast Pacific at $-24 \mathrm{~h}$ and over the Andes at the $0 \mathrm{~h}$ (Figs. 8b,c). On the east coast of South America (south of Brazil, Uruguay, and the South Atlantic Ocean), where the surface cyclogenesis occurred, the BRC term remained positive and varied between 60 and $120 \mathrm{~m}^{2} \mathrm{~s}^{-2}$ day $^{-1}$ until $0 \mathrm{~h}$ when it started to increase. It then reached the maximum of $300 \mathrm{~m}^{2} \mathrm{~s}^{-2}$ day $^{-1}$ over the South Atlantic at $+24 \mathrm{~h}$ (Fig. 8d). The highest baroclinic conversion occurred in the warm zone of the cyclone and was associated with the EKE center development downstream of the trough.

The vertically averaged AFC and ageostrophic flux vector indicate the regions where the energy was exported (negative values) or imported (positive values; Fig. 9). In Fig. 9, we note that there are three main areas where the ageostrophic flux transfers energy from one region to another. These regions are 1) the Southeast Pacific Ocean between $40^{\circ}-25^{\circ} \mathrm{S}$ and $90^{\circ}-80^{\circ} \mathrm{W} ; 2$ ) the Southeast Pacific Ocean between $60^{\circ}-5^{\circ} \mathrm{S}$ and $100^{\circ}-80^{\circ} \mathrm{W}$; and 3 ) the South Atlantic between $45^{\circ}-30^{\circ} \mathrm{S}$ and $50^{\circ}-30^{\circ} \mathrm{W}$. In the first region, the fluxes transfer energy from the Pacific Ocean region to the Andes during the initial $36 \mathrm{~h}$ (Figs. 9a,b); after this period (at $0 \mathrm{~h}$ ) the fluxes start to transfer energy from the Pacific-Andes to the region near the surface cyclogenesis region (Fig. 9c). These fluxes occur at the trough axis and follow its eastward displacement, losing their intensity after the $+12 \mathrm{~h}$ (figure not shown) when the trough is less defined than it was before. The trough axis is a preferential region for transport 

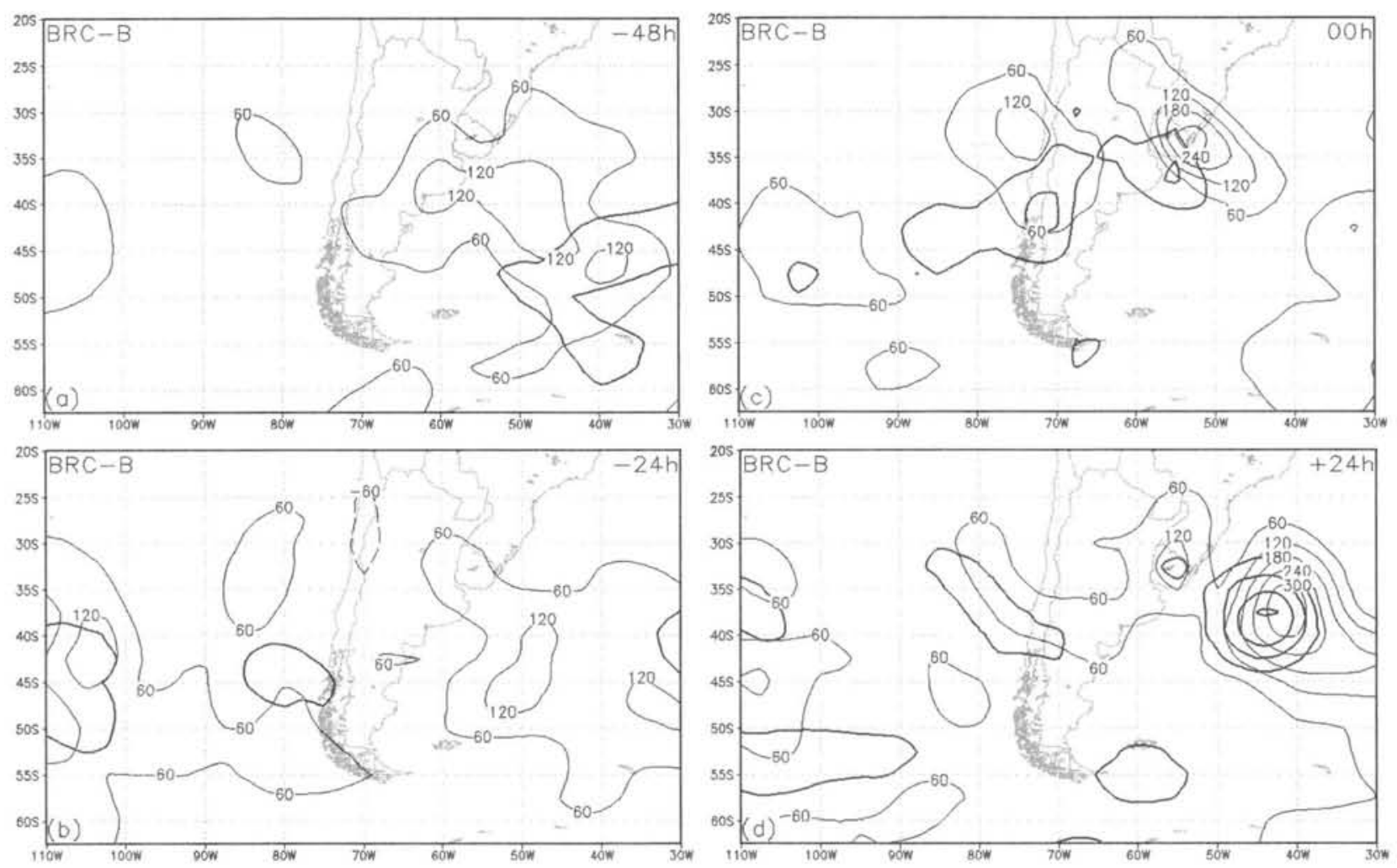

FIG. 8. BRC term (CI $60 \mathrm{~m}^{2} \mathrm{~s}^{-2} \mathrm{day}^{-1}$, zero omitted) and vertically averaged EKE (thick lines, label omitted) for composite B at (a) - 48, (b) -24 , (c) 0 , and (d) $+24 \mathrm{~h}$.

of energy downstream as observed in previous studies (Orlanski and Katzfey 1991; Orlanski and Sheldon 1995). As seen in Fig. 8, mainly between -24 and 0 h, there was BRC conversion to the west of the Andes, in the range of latitude $45^{\circ}-25^{\circ} \mathrm{S}$. The EKE generated by BRC conversion is exported downstream, as observed by ageostrophic flux vectors and the convergence/divergence pattern. In the second region, we can observe that at $-24 \mathrm{~h}$, energy is transported northeast, with maximum energy divergence of $52^{\circ} \mathrm{S}, 85^{\circ} \mathrm{W}$ and convergence of $45^{\circ} \mathrm{S}, 87^{\circ} \mathrm{W}$ and $47^{\circ} \mathrm{S}, 73^{\circ} \mathrm{W}$. This flux explains in part the intensification of the EKE maximum upstream of the trough. In the third area, or near the east coast of South America, the BRC term was positive throughout the period (Fig. 8) and the energy fluxes are toward southeast. The fluxes magnitude increased continuously from -12 to $+24 \mathrm{~h}$ (Figs. 9b-d). As in other areas, here the fluxes transfer local energy generated by BRC conversion in the cyclone region to the area downstream. The energy exported may have been used by another system positioned downstream from the domain. This might have contributed to the development of a less intense coupled trough-cyclone.

Comparing the energy fluxes orientation in the first and third area, it appears that in the first, the energy transfer is more zonal, while the latter has a major me- ridional component. This pattern seems to be associated to the fact that in the first area the energy transfer may happen preferably at high levels where the ageostrophic wind has a greater zonal component. On the other hand, in the third region the transferred energy may preferably occur at low levels where the ageostrophic wind has a major meridional component as shown by Lim et al. (1991) and Kwon and Lim (1999).

In Fig. 9, we can observe an energy convergence over the Andes, between -48 and $-24 \mathrm{~h}$ (Figs. 9a,b) and west of the surface cyclogenesis region at $0 \mathrm{~h}$ (Fig. 9c). This result confirms that the energy generated by BRC conversion occurs (Fig. 8) to the west of the Andes and was exported downstream to the surface cyclogenesis region, as observed in the ageostrophic fluxes field (Fig. 9). While the west region of cyclogenesis received energy by convergence, the east region of cyclogenesis exported energy due to the divergence area (this last area began to develop more clearly from $-12 \mathrm{~h}$, figure not shown). As noted in Fig. 9, the ageostrophic flux divergence transports energy downstream; this energy is generated by $\mathrm{BRC}$ conversion in the surface cyclogenesis region. Also there are a series of positive and negative centers of $\mathrm{AFC}$ between -48 and $-12 \mathrm{~h}$ shaped as an arch in Figs. 9a,b. This sequence of AFC centers at $-24 \mathrm{~h}$ 

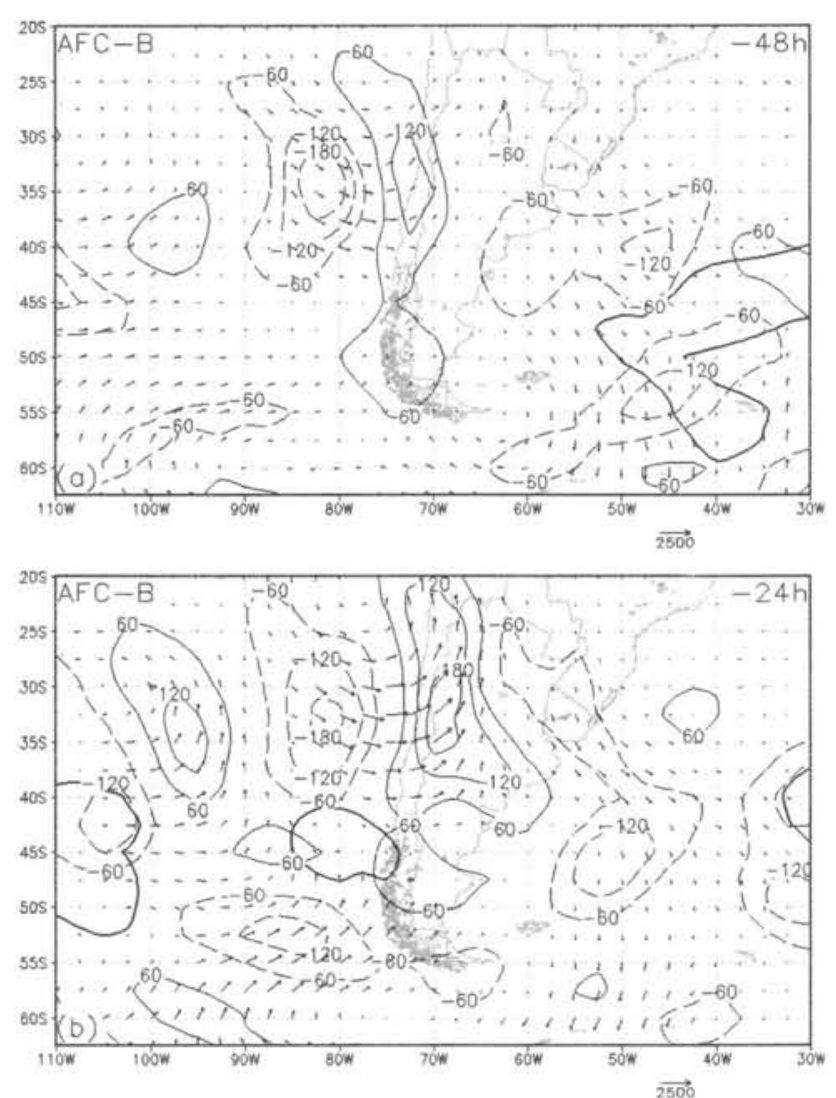

Fig. 9. As in Fig. 8, but for the AFC (CI $60 \mathrm{~m}^{2} \mathrm{~s}^{-2}$ day ${ }^{-1}$, zero omitted) term and ageostrophic flux vectors $\left(\mathrm{m}^{3} \mathrm{~s}^{-3}\right)$.
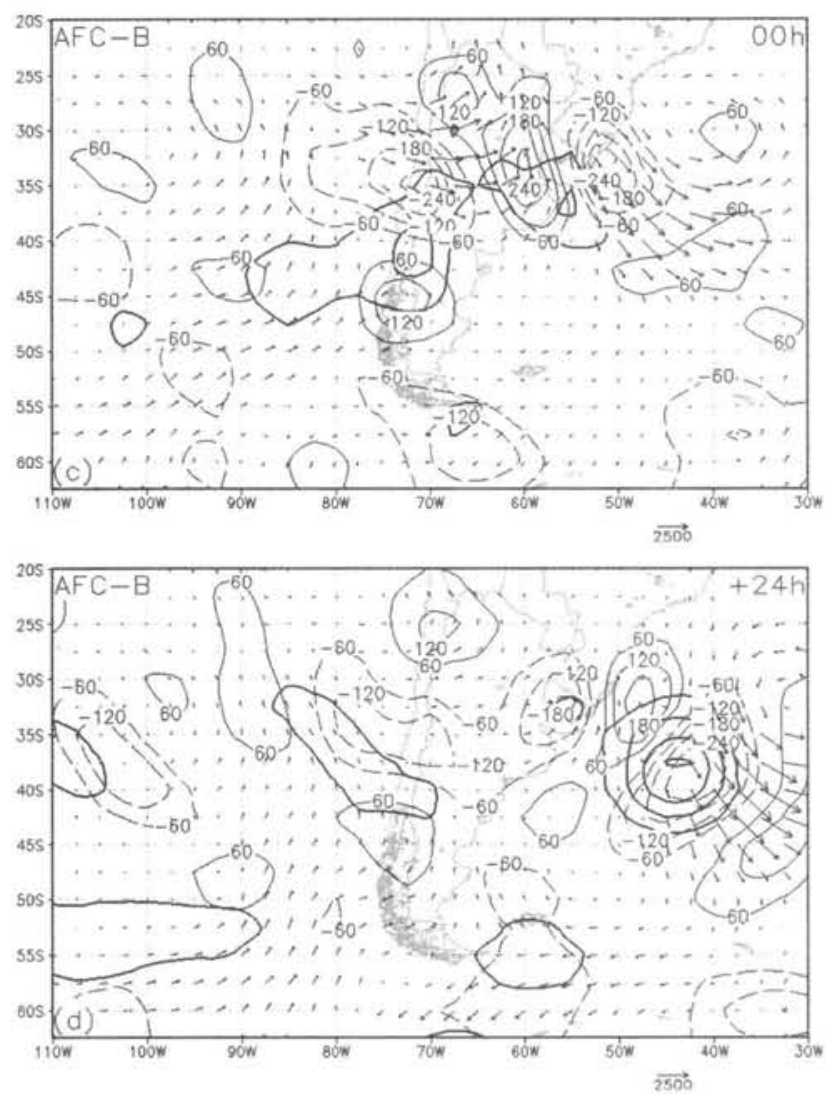

(Fig. 9b) begins with a divergence at $42^{\circ} \mathrm{S}, 105^{\circ} \mathrm{W}$ and ends also in divergence at $45^{\circ} \mathrm{S}, 50^{\circ} \mathrm{W}$. This sequence suggests that there is a transport of energy from the Pacific (at $42^{\circ} \mathrm{S}, 105^{\circ} \mathrm{W}$ ) to the surface cyclogenesis region. It is also interesting to note that the DSBD mechanism proposed by Orlanski and Sheldon (1995), previously discussed, may be related to the development of the EKE center east of the trough. It grows initially by $\mathrm{AFC}$ and then by BRC (baroclinic instability), decaying later by AFC. The same mechanism seems to occur at $0 \mathrm{~h}$ (Fig. $9 \mathrm{c}$ ) when the EKE center at $37^{\circ} \mathrm{S}, 55^{\circ} \mathrm{W}$ grows by AFC (and lightly by BRC conversion, Fig. $8 \mathrm{c}$ ) and at $+24 \mathrm{~h}$ the BRC when conversion is dominant (Fig. 8d). Thus, there is evidence of the DSBD in composite $\mathrm{B}$ and it must be remembered that the DSBD presents a "sequence of events characterizing type-B cyclogenesis, but expressed in terms of eddy kinetic energy" as noted by Orlanski and Sheldon (1995, p.613).

Figure 10 presents the BRT, KFC, and RES terms at $0 \mathrm{~h}$. The BRT term had a different role for each EKE maximum west and east of the trough. Negative values of BRT in the EKE center to the west of the trough show that it decays by barotropic stability. On the other hand, positive values in the eastern energy center indicate that it grows by barotropic instability. It is important to emphasize that in the Lackmann et al. (1999) study, the Reynolds stress was the dominant term during the EKE increase associated with a jet streak in upper levels and it was the precursor of a rapidly intensifying cyclone in the western Atlantic. However, Lackmann et al. (1999) used a different budget equation, where the Reynolds stress is included in the BRT term used in our study. In the western center of trough EKE, the KFC term presents negative values from the center to the northwest, and positive values from the center to the east. This shows its role in moving only the energy center, without influencing the EKE increase or decrease (Orlanski and Katzfey 1991; Chang 2000). The RES term was generally negative and has considerable magnitude over South America and the Atlantic Ocean. Since this term also includes physical processes that are not explained by Eq. (2), the negative values indicate that some physical processes should be included in the equation to reduce the CKT. In this case, the most important process is the EKE dissipation by friction, mainly because the RES had higher values around the region where the surface cyclone developed and it was at its maximum over the continent, where the friction is normally greater. 

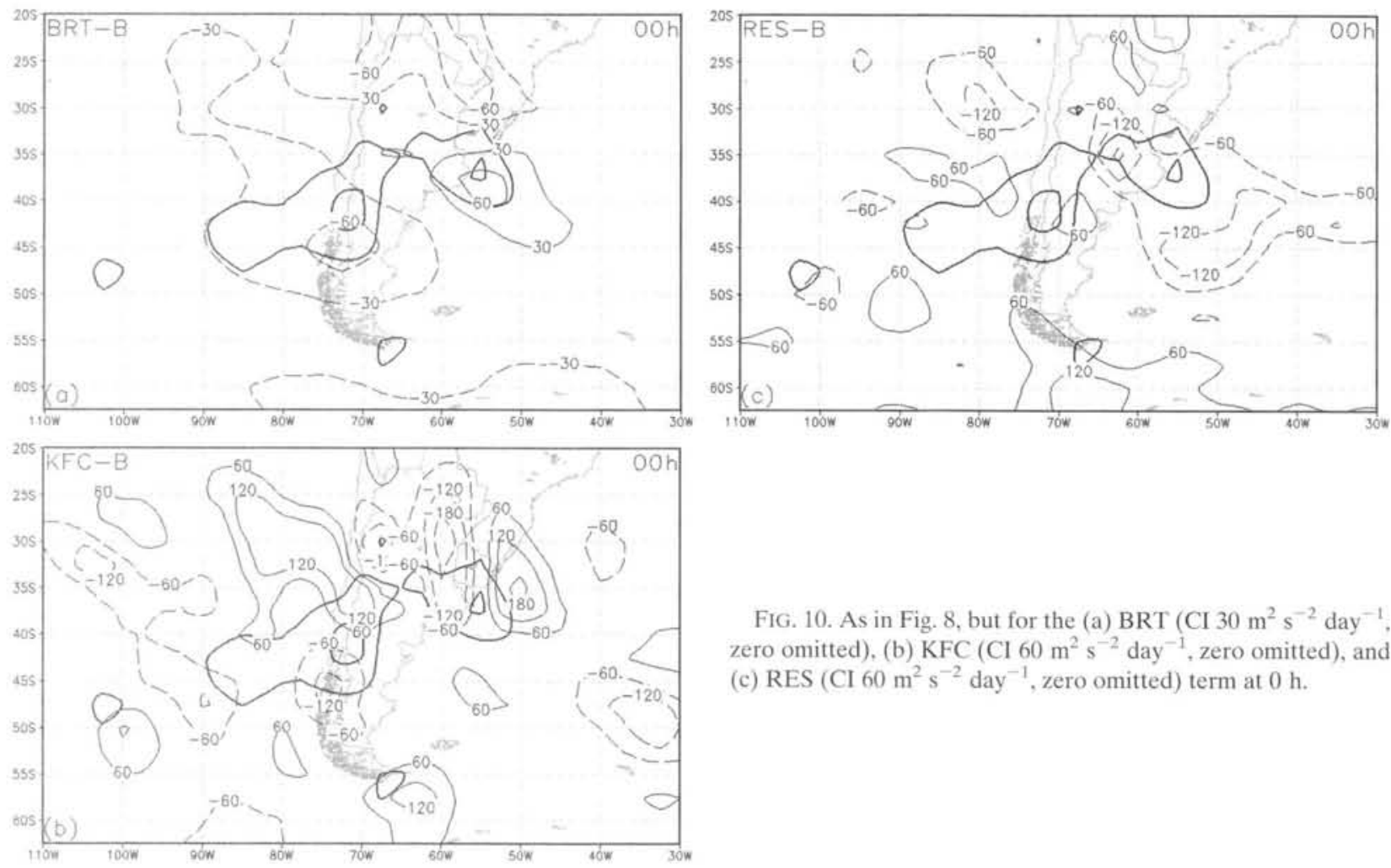

FIG. 10. As in Fig. 8, but for the (a) BRT (CI $30 \mathrm{~m}^{2} \mathrm{~s}^{-2}$ day ${ }^{-1}$. zero omitted), (b) $\mathrm{KFC}\left(\mathrm{Cl} 60 \mathrm{~m}^{2} \mathrm{~s}^{-2}\right.$ day $^{-1}$, zero omitted), and (c) RES (CI $60 \mathrm{~m}^{2} \mathrm{~s}^{-2}$ day $^{-1}$, zero omitted) term at $0 \mathrm{~h}$.

The evolution of the main conversion terms and the EKE evolution and its tendencies (OKT and CKT) are shown in Fig. 11. Only the four conversion terms (BRC, AFC, KFC, and BRT) are shown because they are the dominant processes in the EKE budget. The RES term is averaged in the volume [Eq. (2)] for the area represented by the dashed line in Fig. 7a, also shown in Fig. 11. The EKE starts with values above $100 \mathrm{~m}^{2} \mathrm{~s}^{-2}$ at $-48 \mathrm{~h}$, decreases to values close to $80 \mathrm{~m}^{2} \mathrm{~s}^{-2}$ at $-18 \mathrm{~h}$, and increases at the end of the period with $105 \mathrm{~m}^{2} \mathrm{~s}^{-2}$ at +24 h (Fig. 11a). The CKT was overestimated by approximately $20 \mathrm{~m}^{2} \mathrm{~s}^{-2}$ day $^{-1}$ when compared with OKT. Despite the CKT not showing negative tendency between -48 and $-24 \mathrm{~h}$ as with OKT, there is a reduction in its magnitude. This shows a behavior similar to OKT during the analyzed period (Fig. 11a). The overestimated values of CKT are represented by negative RES values, which remained close to $-20 \mathrm{~m}^{2} \mathrm{~s}^{-2}$ day $^{-1}$ through the period. The analysis of the energy conversion terms shows that the BRC term dominated the entire period, reaching a maximum of $75 \mathrm{~m}^{2} \mathrm{~s}^{-2} \mathrm{day}^{-1}$ at $+18 \mathrm{~h}$, while the other three terms did not exceed $30 \mathrm{~m}^{2} \mathrm{~s}^{-2}$ day ${ }^{-1}$ in absolute values (Fig. 11b). The BRT term was the lowest, it did not reach the values of $-10 \mathrm{~m}^{2} \mathrm{~s}^{-2} \mathrm{day}^{-1}$. The AFC term showed three distinct phases. The former between -48 and -18 h (Figs. $9 \mathrm{a}, \mathrm{b}$ and $11 \mathrm{~b}$ ) when this term was negative showing that the ageostrophic fluxes were exporting energy out of the region. This energy was exported south from latitude $50^{\circ} \mathrm{S}$ between longitudes $60^{\circ}$ and $40^{\circ} \mathrm{W}$; and east along longitude $35^{\circ} \mathrm{W}$ between latitudes $40^{\circ}$ and $50^{\circ} \mathrm{S}$. The second phase of the AFC occurs between -18 and $+12 \mathrm{~h}$ (Figs. $9 \mathrm{c}$ and $11 \mathrm{~b}$ ) when the ageostrophic fluxes are being imported energy into the volume. This energy originated at the upstream region of the Pacific/Andes (see Fig. 9). The last phase of the AFC happens in the last $12 \mathrm{~h}$ of the period when it presents negative values, reflecting the downstream energy propagation that occurs in the eastern boundary of the volume. As the AFC term did not dominate the EKE conversion at any time of the period, the development of the cyclone was not associated with the DSBD. But it is necessary to emphasize that the AFC had a secondary importance in the EKE growth because it only occurred when the AFC became positive (i.e., when the flow stopped exporting energy out of the region). Another important point is that the cyclone only began developing when the AFC reached its maximum at $0 \mathrm{~h}$ (Figs. 11a,b). Even with the BRC conversion increasing fairly and dominating the energy conversions after the cyclone development, it is balanced by the increase of divergent fluxes (AFC negative). This contributes to the initiation of the decay phase as observed by Orlanski and Katzfey (1991), Lackmann et al. (1999), Chang (2000), and McLay and Martin (2002). A similar 

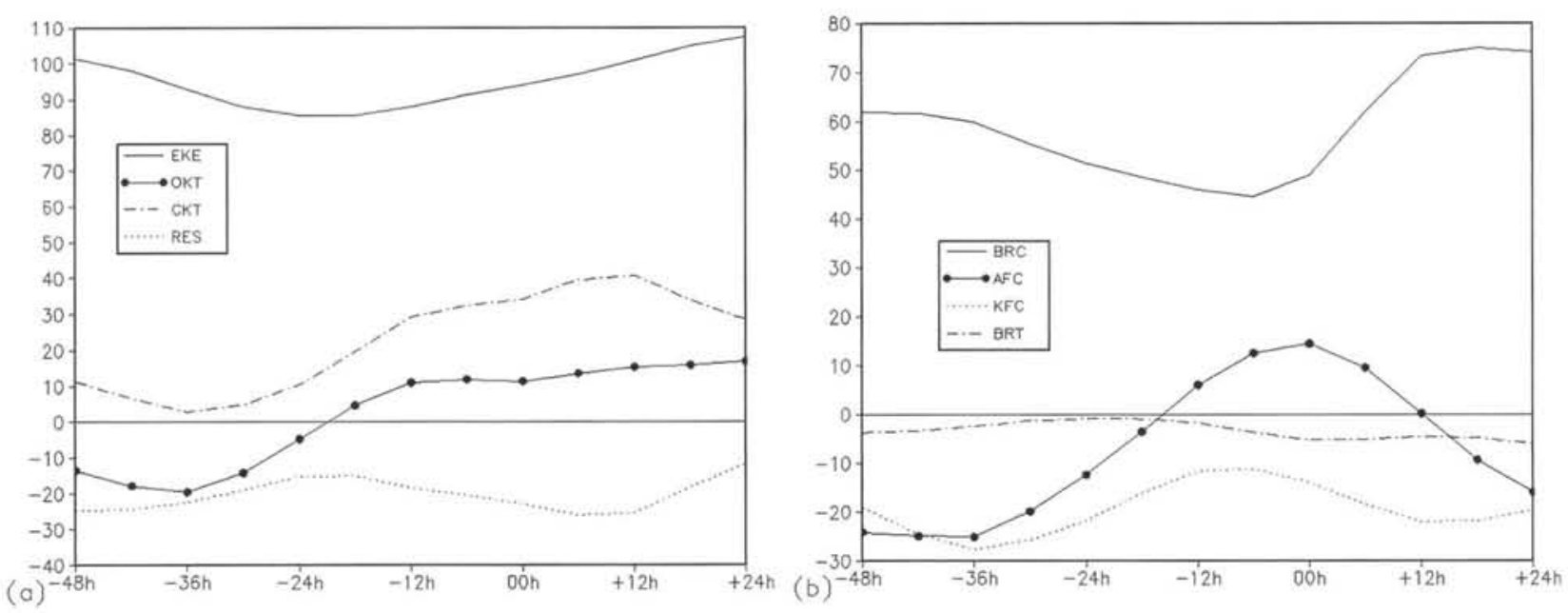

FIG. 11. Temporal evolution of volume-averaged EKE budget for composite B: (a) EKE (solid line), OKT (line with closed circle), CKT (dotted-dashed line), and RES (dotted line) evolution; (b) the evolution of KFC (dotted line), AFC (line with closed circle), BRC (solid line), and BRT (dotted-dashed line). Units are $\mathrm{m}^{2} \mathrm{~s}^{-2}$ day ${ }^{-1}$, except for the EKE unit which is $\mathrm{m}^{2} \mathrm{~s}^{-2}$.

result was obtained by Chen and Bosart (1977) when they studied the energy of cyclone and anticyclone composites in North America. These authors found that after cyclogenesis initiation, the EKE generation in the region became more important than the energy flux going away.
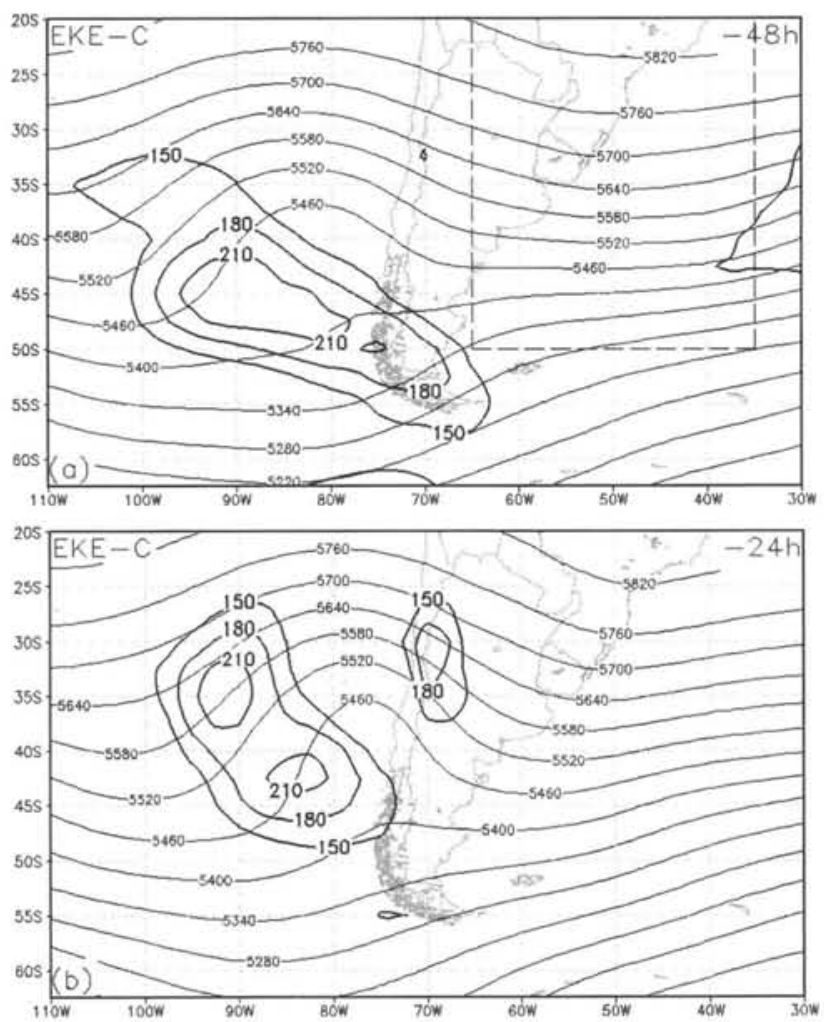

\section{b. Composite $C$}

The vertically averaged EKE for composite C (Fig. 12) shows two major differences in relation to composite B (Fig. 7). The first one refers to the energy maximum to the west of the trough on the southeast Pacific. In this case,

FIG. 12. As in Fig. 7, but for composite C.
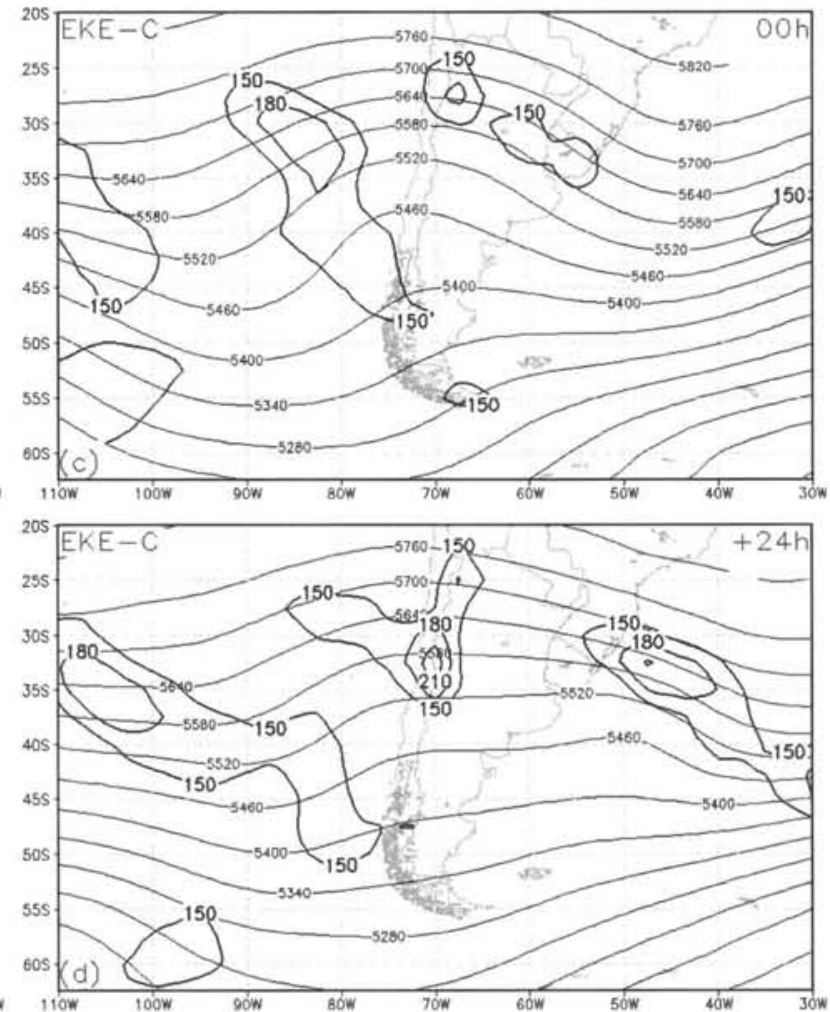

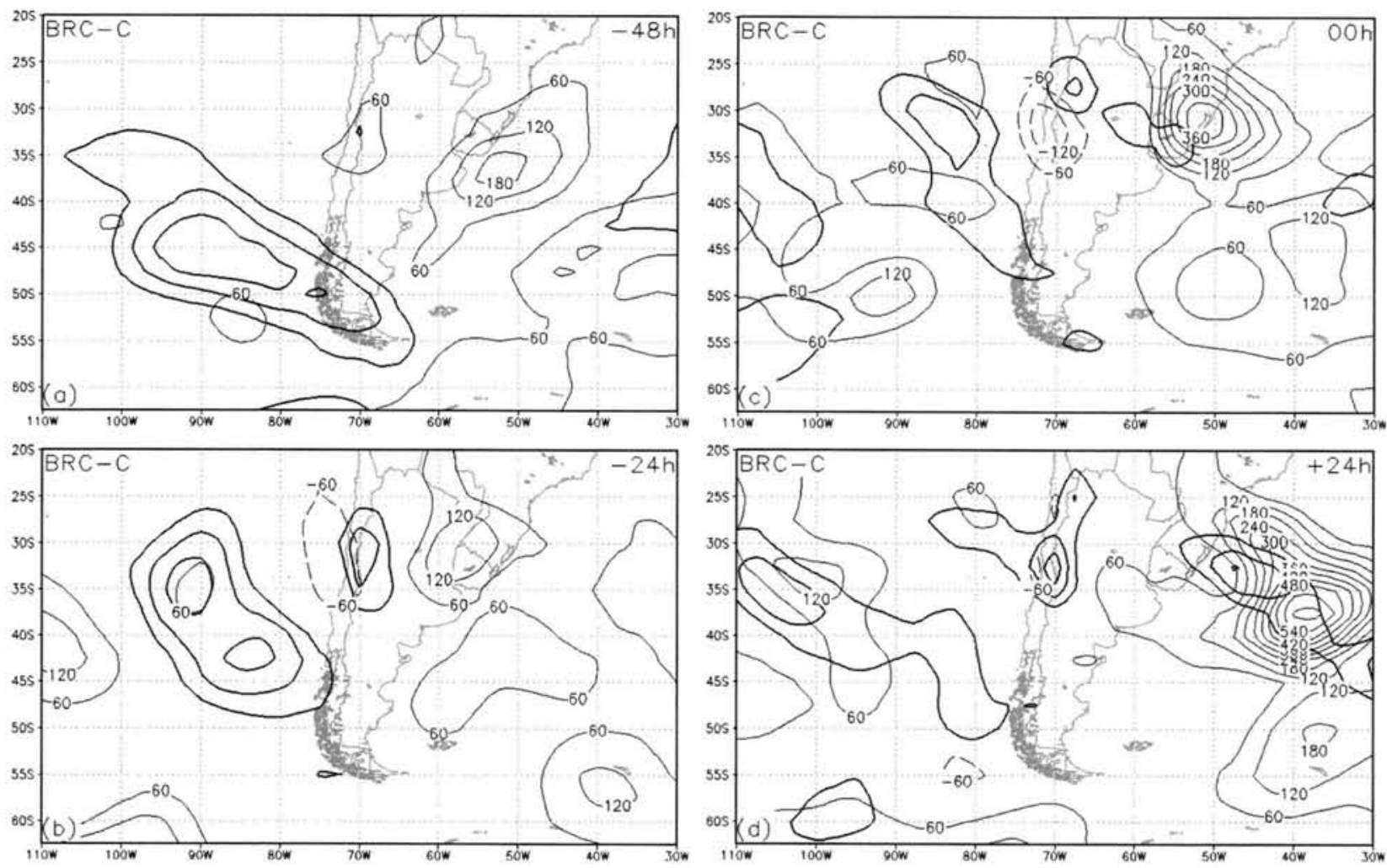

FIG. 13. As in Fig. 8, but for composite C.

the EKE reached values above $210 \mathrm{~m}^{2} \mathrm{~s}^{-2}$ (Fig. 12) while in composite $\mathrm{B}$, the EKE remained less than $180 \mathrm{~m}^{2} \mathrm{~s}^{-2}$ (Figs. 7a-d). This difference in the magnitude of energy reflects the different configurations associated with each composite. In composite $\mathrm{C}$, the trough seemed more amplified than in composite B and a surface cyclone was present over the Pacific Ocean in composite C (Figs. 3-4). The second main difference refers to the magnitude of energy of the center located on the east side of the trough over the cyclogenesis region. It reached a maximum value of $210 \mathrm{~m}^{2} \mathrm{~s}^{-2}$ at $+24 \mathrm{~h}$ in a small area (Fig. 12d), unlike composite B where the energy reached a maximum of $240 \mathrm{~m}^{2} \mathrm{~s}^{-2}$ (Fig. 7d). Despite the fact that the surface cyclone intensity is higher in composite $\mathrm{C}$, the trough in upper levels of South America was seen to be less defined. As the winds were more intense in the upper levels than in the lower, the highest level of energy was found at these levels, which explains why the EKE center is weaker in composite $\mathrm{C}$ than in composite $\mathrm{B}$ during the surface cyclogenesis (Figs. 12c,d).

Despite the presence of a surface cyclone over the southeast Pacific, the BRC conversion in the region was very weak. The reduced positive conversion area, which exceeded $60 \mathrm{~m}^{2} \mathrm{~s}^{-2}$ day $^{-1}$ (Fig. 13), was lower than the BRC conversion observed in composite B (Fig. 8). This result is due to the fact that the cyclones in the southeast
Pacific Ocean are already in the mature or decay stage. But in the surface cyclogenesis region over Uruguay and southern Brazil, the situation was different, and the $\mathrm{BRC}$ conversion was higher in composite $\mathrm{C}$ than in $\mathrm{B}$. For example, at $0 \mathrm{~h}$ the $\mathrm{BRC}$ maximum conversion was $360 \mathrm{~m}^{2} \mathrm{~s}^{-2}$ day $^{-1}$ on the border of Uruguay and southern Brazil (Fig. 13c), while in composite B the maximum was $240 \mathrm{~m}^{2} \mathrm{~s}^{-2}$ day $^{-1}$ (Fig. $8 \mathrm{c}$ ). At $+12 \mathrm{~h}$, the maximum values of BRC conversion in composite $\mathrm{B}$ were observed to be around $420 \mathrm{~m}^{2} \mathrm{~s}^{-2}$ day $^{-1}$ over the South Atlantic, however in composite $\mathrm{C}$ the $\mathrm{BRC}$ conversion was $540 \mathrm{~m}^{2} \mathrm{~s}^{-2}$ day $^{-1}$ (figure not shown). The difference in magnitude of the baroclinic conversion is associated with the intensity of the surface cyclone (stronger SLP decrease). It can also be associated with higher latent heat released (stronger meridional equivalent potential temperature flux) in composite $\mathrm{C}$ than in $\mathrm{B}$. However, in the upper (relative vorticity advection and divergence) and middle (vertical motion) levels the forcing was not stronger in composite $\mathrm{C}$ when compared to composite $\mathrm{B}$ (Fig. 6).

The ageostrophic fluxes as well as the convergence/ divergence patterns became more intense in composite C than in B (Figs. 9 and 14). In this case, three areas of intense fluxes were also observed as in composite $\mathrm{B}$, over 1) the Pacific-Andes between $30^{\circ}$ and $40^{\circ} \mathrm{S}, 2$ ) the 

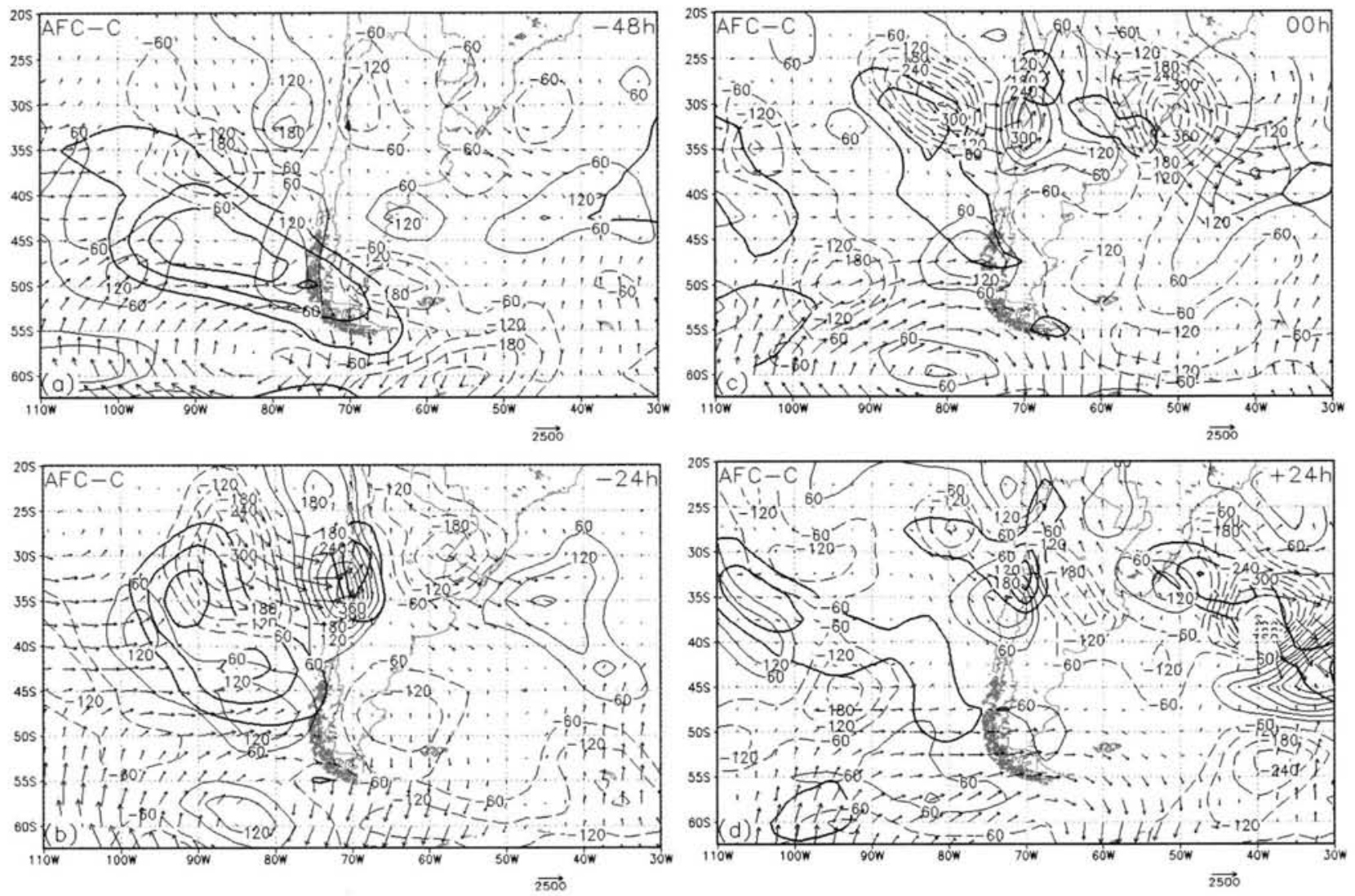

FIG. 14. As in Fig. 9, but for composite C.

southeast Pacific, and 3) the Uruguay and South Atlantic. The main difference between both composites is the presence of cyclonic circulation in composite $\mathrm{C}$ centered at approximately $60^{\circ} \mathrm{S}, 85^{\circ} \mathrm{W}$ at $-24 \mathrm{~h}$ (Fig. 14b), which propagates slowly east. This circulation exported energy out of the region to the south of South America and the Malvinas Islands, and distributed it south and southwest toward the southeast Pacific and west of the Antarctic Peninsula. In composite B, the flow in the area of the Pacific-Andes generated positive AFC over the Andes from -48 to $-24 \mathrm{~h}$, and over the cyclogenesis region at $0 \mathrm{~h}$ (Fig. 9). Meanwhile in composite $\mathrm{C}$, the positive $\mathrm{AFC}$ area is located $10^{\circ}$ farther west than in composite B, centered over the Andes only at $-24 \mathrm{~h}$ (Fig. 14b). In the cyclogenesis region, the flow from the Pacific-Andes did not show a positive AFC region at any time (i.e., the increase of the EKE in the cyclogenesis region did not occur by energy flux from the wave located upstream on the Pacific-Andes). Above the cyclogenesis region, negative $\mathrm{AFC}$ values formed accompanying the cyclone in its southeast displacement (Figs. 14c,d). This divergence was also observed in composite B, but with lower intensity (Figs. 9c,d). The divergence at the beginning of cyclogenesis reached values of $-420 \mathrm{~m}^{2} \mathrm{~s}^{-2}$ day $^{-1}$ (Fig. 14c) while in composite B the maximum magnitude was of $-240 \mathrm{~m}^{2} \mathrm{~s}^{-2}$ day $^{-1}$ (Fig. 9c). The negative AFC increased up to the end of the studied period, reaching $-540 \mathrm{~m}^{2} \mathrm{~s}^{-2}$ day $^{-1}$ around $37.5^{\circ} \mathrm{S}, 40^{\circ} \mathrm{W}$ at +24 h (Fig. $14 \mathrm{~d}$ ). Meanwhile, in composite $\mathrm{B}$, the negative AFC near the cyclone reached the maximum of $-360 \mathrm{~m}^{2} \mathrm{~s}^{-2}$ day $^{-1}$ at $+12 \mathrm{~h}$ (figure not shown), decreasing later. The negative AFC values in the region between southern South America and around the Malvinas Islands were due to the cyclonic circulation (recirculation) centered at $60^{\circ} \mathrm{S}, 85^{\circ} \mathrm{W}$ commented on earlier. This recirculation has been observed in previous studies (Orlanski and Katzfey 1991; Orlanski and Sheldon 1995). And, as Decker and Martin (2005) mentioned, it can be associated to the lifetime increase of the EKE maximum because the recirculation delays the decay that would occur through divergence of the ageostrophic geopotential flux.

The BRT term was negative in most of the domain, similar to composite B, but the Antarctic Peninsula showed elevated negative values (Fig. 15). The negative values of BRT probably can be interpreted as Rossby wave radiation forced by Antarctic topography, however, further studies are necessary to confirm this interpretation 

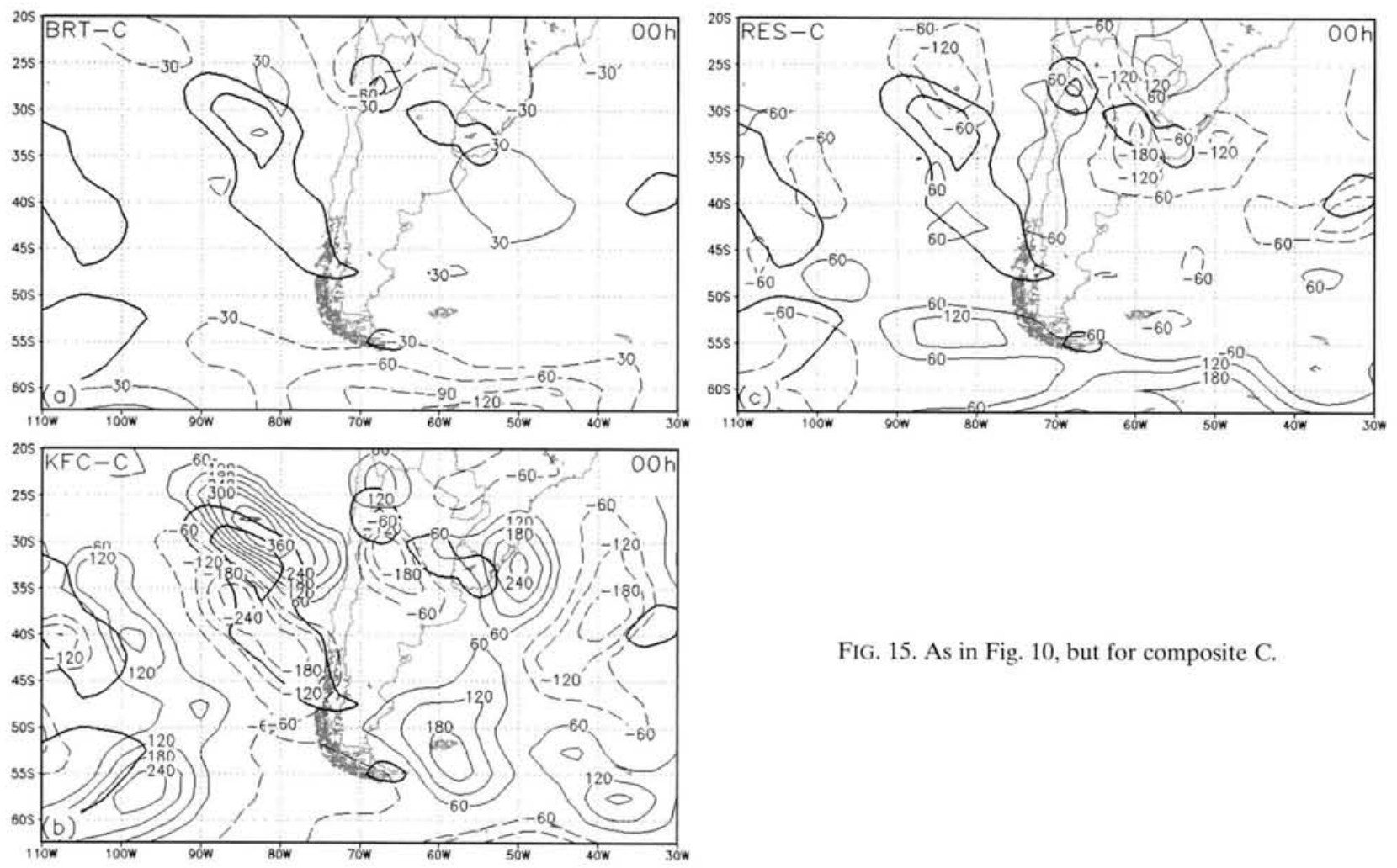

FIG. 15. As in Fig. 10, but for composite C.

because in composite B the BRT conversion was weak in this area. As in composite B, the EKE center in the cyclogenesis region gains energy from the mean flow through the BRT positive term, but the mean flow also takes eddy kinetic energy by BRT conversion in the northern portion of the EKE center over the cyclogenesis region between +12 and $+24 \mathrm{~h}$ (figure not shown). The KFC term shows the northward displacement of the energy center west of the trough and the eastward dis-

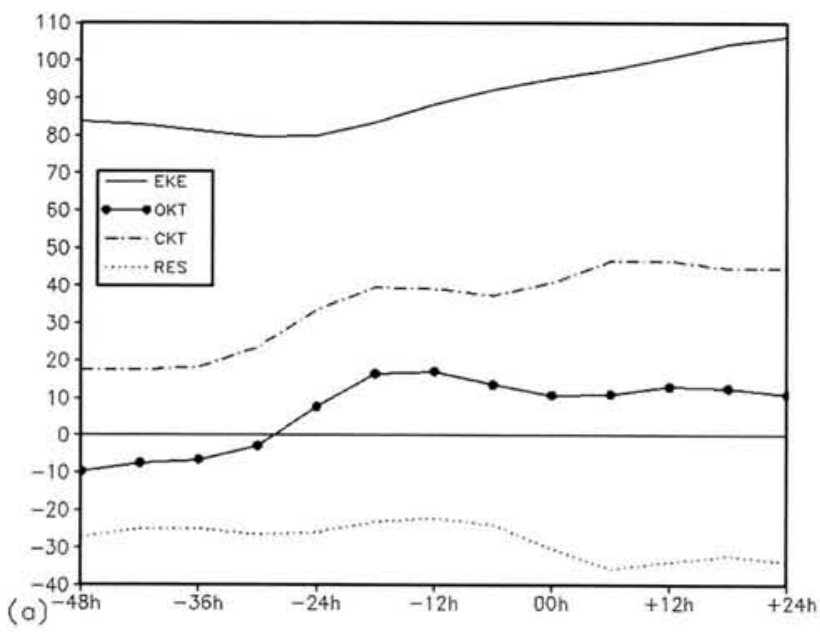

placement of the energy center on the east side of the trough over South America (Fig. 15b). As for composite $\mathrm{B}$, the RES term was generally negative, but there are high positive values in the Antarctica region (Fig. 15c).

The volume-averaged EKE (Fig. 16) shows that the EKE decreased slightly during the first $24 \mathrm{~h}$ (from -48 to $-24 \mathrm{~h}$ ), reaching a minimum of $80 \mathrm{~m}^{2} \mathrm{~s}^{-2}$ at $-24 \mathrm{~h}$. After that, a linear growth phase began up the end of the period (Fig. 16a). As in composite B, the OKT was lower

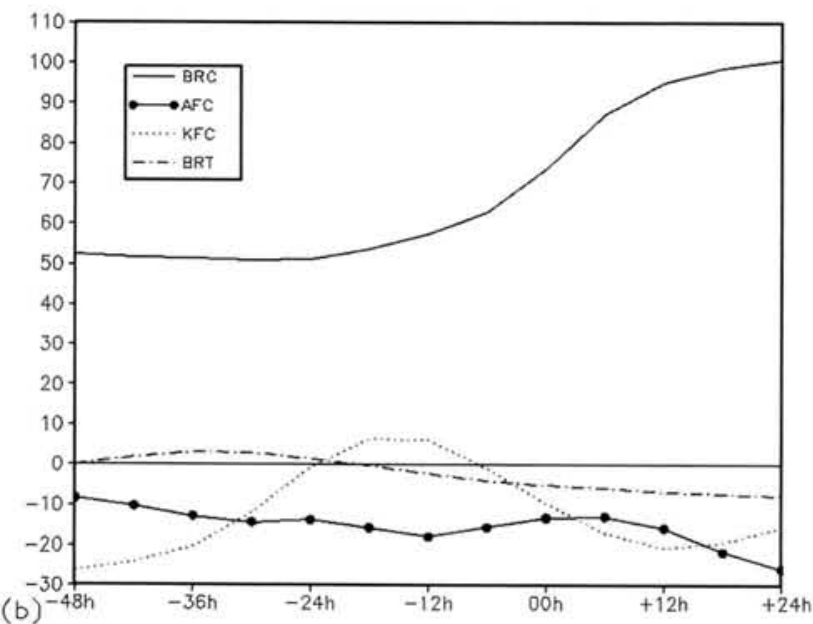

FIG. 16. As in Fig. 11, but for composite C. 
than CKT as indicated by the RES term (around of $-30 \mathrm{~m}^{2} \mathrm{~s}^{-2}$ day $^{-1}$ ), but both terms show a similar behavior with time. We cannot determine which mechanism explains the initial phase with negative OKT because CKT remained positive throughout the period. In this period, the dominant conversion term was the BRC as was observed in composite B (Figs. 11b and 16b). Its values remained under $60 \mathrm{~m}^{2} \mathrm{~s}^{-2}$ day $^{-1}$ until $6 \mathrm{~h}$ before the formation of the cyclone $(-6 \mathrm{~h})$, when a rapid growth phase began, reaching around $100 \mathrm{~m}^{2} \mathrm{~s}^{-2} \mathrm{day}^{-1}$ at the end of the period $(+24 \mathrm{~h})$. The BRT term remained smaller (in absolute values) than $10 \mathrm{~m}^{2} \mathrm{~s}^{-2} \mathrm{day}^{-1}$, and did not play an important role in the development/decay of EKE. The convergence terms (KFC and AFC) showed negative values during most of the period. The KFC term presented positive values during $18 \mathrm{~h}$ (between -24 and $-6 \mathrm{~h}$ ), but with a magnitude lower than $10 \mathrm{~m}^{2} \mathrm{~s}^{-2} \mathrm{day}^{-1}$. The AFC was always negative, exporting energy out of the volume from the south $\left(50^{\circ} \mathrm{S}\right)$ and east $\left(35^{\circ} \mathrm{W}\right)$ boundaries at different periods (Fig. 14). Before the cyclone formation, the energy was exported upstream from the southern boundary of the volume as discussed previously when the recirculation in the ageostrophic fluxes and AFC were analyzed (Figs. 14a,b). After the formation of the cyclone, the energy is exported downstream to southeast through the east boundary as observed near $35^{\circ} \mathrm{S}, 40^{\circ} \mathrm{W}$ (Figs. $14 \mathrm{c}, \mathrm{d}$ ). Unlike composite $\mathrm{B}, \mathrm{AFC}$ did not appear to play an important role in the volume-averaged energetics.

\section{Conclusions}

For five winter periods from 1999 to 2003, we analyzed all cases in which a $500-\mathrm{hPa}$ trough crossed South America and triggered surface cyclogenesis in Uruguay or the adjacent areas. A total of 38 cases were divided into two composites named composite B (with 25 cases) and composite $\mathrm{C}$ (with 13 cases).

A comparative study of the two composites showed that the trough over the South Pacific Ocean was less intense in composite $\mathrm{B}$ than in composite $\mathrm{C}$, but became more intense after crossing the Andes. The midtroposphere trough identified in both composites showed that the trough was less (more) intense on the South Pacific Ocean (crossing the Andes) in composite B (C) before (during) surface cyclogenesis phase. From the variables analyzed in the lower, middle, and upper troposphere, only the meridional equivalent potential temperature flux showed differences, its magnitude being higher in composite $\mathrm{C}$ than in $\mathrm{B}$. The results also show that the meridional heat and moisture fluxes in lower levels had a crucial role in surface cyclogenesis. As previous studies have shown, this meridional flow serves as precondi- tioning to the formation of the cyclone (i.e., its effect occurs in the phase prior to the onset of the cyclogenesis). The analysis of composites $\mathrm{B}$ and $\mathrm{C}$ shows that the heat and moisture flow was intense at $48 \mathrm{~h}$ prior to cyclogenesis, attaining the maximum at $12 \mathrm{~h}$ before it. Although the flow was important for both composites, it was more intense in composite $\mathrm{C}$. This shows the role of mountains in blocking the propagation of cold air from the South Pacific Ocean, and allowing the intensification of the warm air advection on the lee side of the Andes, as observed in the formation of the lee cyclogenesis in the Alps by Radinovic (1986).

The baroclinic conversion was higher in composite $\mathrm{C}$ than in B, reflecting the more intense surface cyclogenesis in composite $\mathrm{C}$, despite the higher kinetic energy in composite B. This contradiction appears because kinetic energy was higher at upper levels where the winds are more intense in composite B. The ageostrophic energy flux, responsible for downstream development, was more intense in composite $\mathrm{C}$. This flux is important in energy export and import upstream and downstream of the cyclogenesis region, respectively.

The conversion terms averaged in the volume showed that there are some differences in the energetics of the two composites. The baroclinic conversion was dominant in the two composites, but more intense in composite $\mathrm{C}$. In composite $\mathrm{B}$, the $\mathrm{AFC}$ contributed positively to the intensification of the surface cyclone because it imported energy into the domain before the beginning of the cyclogenesis. On the other hand, in composite $\mathrm{C}$ the AFC served as a sink because it exported energy out of the domain.

Based on these results, it is possible to conclude that for both composites 1) the trough was crucial for the cyclogenesis; 2) the variables in lower, middle, and upper levels did not differ from one composite to another; 3 ) the northerly heat and moisture flow acted as a preconditioning for the cyclogenesis, mainly for composite-C; 4) the baroclinic conversion dominated the energetics; and 5) the ageostrophic flux convergence had a secondary role. It contributed negatively to the development of the cyclone in composite $\mathrm{C}$ and positively to the initial development of the cyclone in composite B.

The surface cyclones in composites B and C seem to develop in the middle and in the upstream edge of the wavepackets, respectively. This conjecture was based on the Decker and Martin (2005) study, which analyzed two cyclogenesis events. During the first one, the associated EKE center developed before the surface cyclone, the AFC term was negative, and the cyclogenesis happened upstream from the wave packet. During the second cyclogenesis event, the associated EKE center developed together with the surface cyclone, the AFC term was 
near zero, and the cyclogenesis happened in the midst of the wave packet. Here, in the composite $\mathrm{C}$, the associated EKE center developed $24 \mathrm{~h}$ before the surface cyclone and the $\mathrm{AFC}$ term was negative. In the composite $\mathrm{B}$, the associated EKE center developed $12 \mathrm{~h}$ before the surface cyclone and the AFC term was positive. Thus, it seems that composite $\mathrm{C}$ is more dispersive than composite $\mathrm{B}$ and the surface cyclogenesis seems to happen in a different position in relation to the wave packet.

Acknowledgments. This paper is part of the Ph.D. thesis of the first author. Thanks are due to the Conselho Nacional de Desenvolvimento Científico e Tecnológico (CNPq, Project 381246/2007-8) and Coordenação de Aperfeiçoamento de Pessoal de Nível Superior (CAPES) for the first author's Ph.D. scholarship. The authors also thank Dr. E. J. M. Chang for his help.

\section{REFERENCES}

Berbery, E. H., and C. S. Vera, 1996: Characteristics of the Southern Hemisphere winter winter storm tracks with filtered and unfiltered data. J. Atmos. Sci., 53, 468-481.

Buzzi, A., and S. Tibaldi, 1978: Cyclogenesis in the lee of the Alps: A case study. Quart. J. Roy. Meteor. Soc., 104, 271-287.

Chang, E. K. M., 2000: Wave packets and life cycles of troughs in the upper troposphere: Examples from the Southern Hemisphere summer season of 1984/85. Mon. Wea. Rev,, 128, $25-50$.

Chen, T.-J., and L. F. Bosart, 1977: Quasi-Lagrangian kinetic energy budget of composite-cyclone-anticyclone couplets. J. Atmos. Sci., 34, 452-464.

Danielson, R. E., J. R. Gyakum, and D. N. Straub, 2006a: A case study of downstream baroclinic development over the North Pacific Ocean. Part I: Dynamical impacts. Mon. Wea. Rev., 134, 1534-1548.

,-- , and $-2006 \mathrm{~b}$ : A case study of downstream baroclinic development over the North Pacific Ocean. Part II: Diagnoses of eddy energy and wave activity. Mon. Wea. Rev., 134, 15491567.

Dare, P. M., and P. J. Smith, 1984: A comparison of observed and model energy balance for an extratropical cyclone system. Mon. Wea. Rev., 112, 1289-1308.

Dean, D. B., and L. F. Bosart, 1996: Northern Hemisphere 500-hPa trough merger and fracture: A climatology and case study. Mon. Wea. Rev., 124, 2644-2671.

Decker, S. G., and J. E. Martin, 2005: A local energetics analysis of the life cycle differences between consecutive, explosively deepening, continental cyclones. Mon. Wea. Rev., 133, 295-316.

Eddy, A., 1965: Kinetic energy production in a mid-latitude storm. J. Appl. Meteor., 4, 569-575.

Fuenzalida, H. A., R. Sánchez, and R. Garreaud, 2005: A climatology of cutoff lows in the Southern Hemisphere. J. Geophys. Res., 110, D18101, doi:10.1029/2005JD005934.

Funatsu, B. M., M. A. Gan, and E. Caetano Neto, 2004: A case study of orographic cyclogenesis over South America. Atmósfera, 17, 91-113.

Gan, M. A., and V. B. Rao, 1991: Surface cyclogenesis over South America. Mon. Wea. Rev., 119, 1293-1302.
— , and - 1994: The influence of the Andes Cordillera on transient disturbances. Mon. Wea. Rev., 122, 1142-1157.

$\longrightarrow$, and -1996 : Case studies of cyclogenesis over South America. Meteor. Appl., 3, 359-369.

Hodges, K. I., B. J. Hoskins, J. Boyle, and C. Thorncroft, 2003: A comparison of recent reanalysis datasets using objective feature tracking: Storm tracks and tropical easterly waves. Mon. Wea. Rev., 131, 2012-2037.

Holton, J. R., 1992: An Introduction to Dynamic Meteorology. International Geophysics Series, Vol. 48, Academic Press, $350 \mathrm{pp}$.

Innocentini, V., and E. Caetano Neto, 1996: A case study of the 9 August 1988 South Atlantic storm: Numerical simulations of the wave activity. Wea. Forecasting, 11, 78-88.

Kalnay, E., and Coauthors, 1996: The NCEP/NCAR 40-Year Reanalysis Project. Bull. Amer. Meteor. Soc., 77, 437-471.

Keable, M., I. Simmonds, and K. Keay, 2002: Distribution and temporal variability of $500-\mathrm{hPa}$ cyclone characteristics in the Southern Hemisphere. Int. J. Climatol., 22, 131-150.

Kung, E. C., 1977: Energy sources in middle-latitude synoptic-scale disturbances. J. Atmos. Sci., 34, 1352-1365.

Kwon, H. J., and G. H. Lim, 1999: Reexamination of the structure of the ageostrophic wind in baroclinic waves. J. Atmos. Sci., 56, 2513-2521.

Lackmann, G. M., D. Keyser, and L. F. Bosart, 1999: Energetics of an intensifying jet streak during the Experiment on Rapidly Intensifying Cyclones over the Atlantic (ERICA). Mon. Wea. Rev., 127, 2777-2795.

Lefevre, R. J., and J. W. Nielsen-Gammon, 1995: An objective climatology of mobile troughs in the Northern Hemisphere. Tellus, 47A, 638-655.

Lim, E. P., 2005: Global changes in synoptic activity with increasing $\mathrm{CO}_{2}$. Ph.D. thesis, The University of Melbourne, Victoria, Australia, $381 \mathrm{pp}$.

, and I. Simmonds, 2007: Southern Hemisphere winter extratropical cyclone characteristics and vertical organization observed with the ERA-40 data in 1979-2001. J. Climate, 20, 2675-2690.

Lim, G. H., J. R. Holton, and J. M. Wallace, 1991: The structure of the ageostrophic wind field in baroclinic waves. J. Atmos. Sci., 48, 1733-1745.

Marengo, J., A. Cornejo, P. Satyamurty, and C. Nobre, 1997: Cold surges in tropical and extratropical South America: The strong event in June 1994. Mon. Wea. Rev., 125, 2759-2786.

Marques, C. A. F., A. Rocha, J. Corte-Real, J. M. Castanheira, J. Ferreira, and P. Melo-Gonçalves, 2009: Global atmospheric energetics from NCEP-Reanalysis 2 and ECMWF-ERA-40 Reanalysis. Int. J. Climatol., 29, 159-174, doi:10.1002/joc.1704.

Masters, S. E., and E. C. Kung, 1986: An energetics analysis of cyclonic development in the Asian winter monsoon. J. Meteor. Soc. Japan, 64, 35-51.

McGinley, J. A., 1982: A diagnosis of Alpine lee cyclogenesis. Mon. Wea. Rev., 110, 1271-1287.

McLay, J. G., and J. E. Martin, 2002: Surface cyclolysis in the North Pacific Ocean. Part III: Composite local energetics of tropospheric-deep cyclone decay associated with rapid surface cyclolysis. Mon. Wea. Rev., 130, 2507-2529.

Mendes, D., E. P. Souza, I. F. Trigo, and P. M. A. Miranda, 2007: On precursors of South American Cyclogenesis. Tellus, 59A, 114-121.

Nielsen-Gammon, J. W., 1995: Dynamical conceptual models of upper-level mobile trough formation: Comparison and application. Tellus, 47A, 705-721. 
Orlanski, 1., and J. Katzfey, 1991: The life cycle of cyclone wave in the Southern Hemisphere. Part I: Eddy energy budget. J. Atmos. Sci., 48, 1972-1998.

— , and J. P. Sheldon, 1993: A case of downstream baroclinic development over western North America. Mon. Wea. Rev., 121, 2929-2950.

$\longrightarrow$, and 1995: Stages in the energetics of baroclinic systems. Tellus, 47A, 605-628.

Petterssen, S., and S. J. Smebye, 1971: On the development of extratropical cyclones. Quart. J. Roy. Meteor. Soc., 97, 457-482.

Piva, E. D., M. A. Gan, and V. B. Rao, 2008a: An objective study of $500-\mathrm{hPa}$ moving troughs in the Southern Hemisphere. Mon. Wea. Rev., 136, 2186-2200.

_. M. C. L. Moscati, and M. A. Gan, 2008b: Papel dos fluxos de calor latente e sensivel em superfície associado a um caso de ciclogênese na costa leste da América do Sul (Role of surface latent and sensible heat fluxes associated to a South America east coast cyclogenesis case). Brazilian J. Meteor., 23, $450-476$.

Plant, R. S., G. C. Craig, and S. L. Gray, 2003: On the threefold classification of extratropical cyclogenesis. Quart. J. Roy. Meteor. Soc., 129, 2989-3012.

Radinovic, D., 1986: On the development of orographic cyclones. Quart. J. Roy. Meteor. Soc., 112, 927-951.

Randel, W. J., and J. L. Stanford, 1985a: An observational study of medium-scale wave dynamics in the Southern Hemisphere summer. Part I: Wave structure and energetics. J. Atmos. Sci, 42, 1172-1188.

- and $-1985 \mathrm{~b}$ : An observational study of medium-scale wave dynamics in the Southern Hemisphere summer. Part II: Stationary-transient wave interference. I. Atmos. Sci., 42, 1189-1197.

Rao, V. B., A. M. C. do Carmo, and S. H. Franchito, 2002: Seasonal variations in the Southern Hemisphere storm tracks and associated wave propagation. J. Atmos. Sci., 59, 1029-1040.
Sanders, F., 1986: Explosive cyclogenesis in the west-central North Atlantic Ocean, 1981-1984. Part I: Composite structure and mean behavior. Mon. Wea. Rev., 114, 1781-1794.

- 1988: Life history of mobile troughs in the upper westerlies. Mon. Wea. Rev., 116, 2759-2786.

Seluchi, M. E., 1995: Diagnóstico y pronóstico de situaciones sinópticas conducentes a ciclogénesis sobre el este de Sudamérica (Diagnostic and prognostic of the synoptic situations tiggering to cyclogenesis on the South America). Geophys. Int., 34, 171-186.

- , and A. C. Saulo, 1998: Possible mechanisms yielding an explosive coastal cyclogenesis over South America: Experiment using a limited area model. Aust. Meteor. Mag., 47, 309-320.

Simmonds, I., and K. Keay, 2000: Mean Southern Hemisphere extratropical cyclone behavior in the 40-Yr NCEP-NCAR reanalysis. J. Climate, 13, 873-885.

— , and E.-P. Lim, 2009: Biases in the calculation of Southern Hemisphere mean baroclinic eddy growth rate. Geophys. Res. Lett., 36, L01707, doi:10.1029/2008GL036320.

Sinclair, M. R., 1994: An objective cyclone climatology for the Southern Hemisphere. Mon. Wea. Rev., 122, 2239-2256.

— 1995: A climatology of cyclogenesis for the Southern Hemisphere. Mon. Wea. Rev., 123, 1601-1619.

Smith, P. J., 1973: The kinetic energy budget over North America during a period of major cyclone development. Tellus, 25, 411-423.

- 1980: The energetics of extratropical cyclones. Rev. Geophys. Space Phys., 18, 378-386.

Vera, C. S., P. K. Vigliarolo, and E. H. Berbery, 2002: Cold season synoptic-scale waves over subtropical South America. Mon. Wea. Rev., 130, 684-699.

Wang, X. L., V. R. Swail, and F. W. Zwiers, 2006: Climatology and changes of extratropical cyclone activity: Comparison of ERA-40 with NCEP-NCAR reanalysis for 1958-2001. J. Climate, 19, 3145-3166. 


\section{COPYRIGHT INFORMATION}

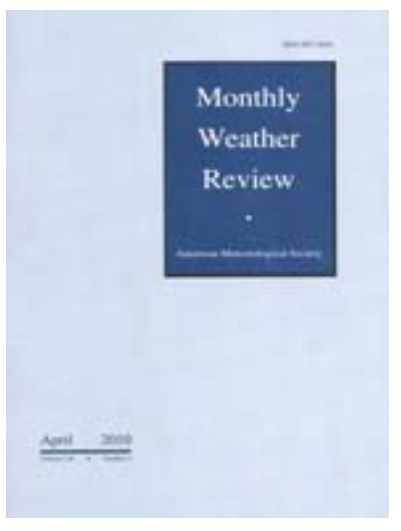

Author: Piva, Everson Dal; Gan, Manoel A.; Rao, V. Brahmananda

Title: Energetics of Winter Troughs Entering South America

Source: Mon Weather Rev 138 no4 Ap 2010 p. 1084-103

ISSN: 0027-0644

DOI: $10.1175 / 2009 M W R 2970.1$

Publisher: American Meteorological Society

45 Beacon Street, Boston, MA 02108-3693

The magazine publisher is the copyright holder of this article and it is reproduced with permission. Further reproduction of this article in violation of the copyright is prohibited. To contact the publisher: http://www.ametsoc.org/AMS/

This article may be used for research, teaching and private study purposes. Any substantial or systematic reproduction, re-distribution, re-selling, loan or sublicensing, systematic supply or distribution in any form to anyone is expressly forbidden. The publisher does not give any warranty express or implied or make any representation that the contents will be complete or accurate or up to date. The accuracy of any instructions, formulae and drug doses should be independently verified with primary sources. The publisher shall not be liable for any loss, actions, claims, proceedings, demand or costs or damages whatsoever or howsoever caused arising directly or indirectly in connection with or arising out of the use of this material. 